\title{
Guido Woldering* \\ Über die Idee und das Wirkliche (Teil II)
}

DOI 10.1515/asia-2017-2303

Zusammenfassung: Dieser Beitrag setzt die in der vorangehenden Nummer der Asiatischen Studien begonnene Übersetzung der Summe von Ishibashi Ningetsus (石橋忍月, 1865-1926) poetologischen Überlegungen fort. Die literaturhistorische Bedeutung des Texts besteht in der Einführung eines weder regional noch historisch eingeschränkten, ausserdem auch alle Textsorten einschliessenden Konzepts der „Poesie“ (shi 詩), das sich klar vom klassischen Begriff der Schriftgelehrsamkeit (bungaku 文学) unterscheidet. Die japanische Literatur entwickelt sich nun deutlich zu einem vollwertigen Bestandteil eines autonomen Feldes „Kunst“. Eine weitere Leistung des Sō jitsu ron besteht in der Integration traditioneller japanischer und moderner europäischer theoretischer Ansätze. Das macht den Text zu einem Meilenstein auf dem Weg zu einer selbständigen japanischen wissenschaftlich-theoretischen Auseinandersetzung mit der eigenen Literatur.

Schlüsselwörter: Literaturtheorie, Intertextualität, Literaturbegriff, Textsorten

\section{Charakter der Idee und des Wirklichen}

Grob unterschieden gibt es zwei Urquellen der Poesie. Die eine nenne ich die Idee, die andere das Wirkliche. Die Idee ist die gestaltlose Vorstellung, das Wirkliche ist die wahrnehmbare Gestalt. ${ }^{1}$ Die wahrnehmbare Gestalt kann man festhalten, die

1 „Wahrnehmbare Gestalt“ für shinkei 真景 bezeichnet hier die ausserhalb der Poesie bestehende, empirisch nachvollziehbare Wirklichkeit (Erscheinungswelt). „Gestaltlose Vorstellung“ für kyoshō 虚象. Als literaturtheoretischer Terminus ist diese Zusammensetzung nicht verifizierbar. Das darin enthaltene kyo 虚 ist hier im Sinne von „Abwesenheit“ (DKJ 9-32709) zu interpretieren, shō 象 im Sinne von „Gestalt“ (DKJ 10-36372). Ishibashi meint hier die noch nicht in eine (sprachliche oder sonst darstellende) Form gegossene Idee und bezieht sich inhaltlich deutlich auf die seit Futabatei Shimeis „Shōsetsu sōron 小説総論“ („Allgemeine Abhandlung über den Roman“, 1886) geführte Diskussion der begrifflichen Dichotomie „Form“ - „Idee“ (bei Futabatei in den Termini fōmu フホーム [< engl. form] 形 und aidia ア

Originaltitel: Sō jitsu ron 想實論, von Ishibashi Ningetsu 石橋忍月

*Corresponding author: Guido Woldering, Privatgelehrter, Frankfurt am Main, Germany.

E-mail: guido.woldering@gmail.com 
gestaltlose Vorstellung kann man nicht festhalten. So ist also das äusserste Ende der Seele das Wirkliche, das äusserste Ende des Geistes die Idee. ${ }^{2}$ Das Material der Poesie ist schliesslich überall $\mathrm{zu}$ finden, und deswegen ist der Poet auch an jedwedem Ort in Stadt und Land zu Hause. Das Gewichtigste aber, auf das der Poet sein Augenmerk richtet, ist das Leben des Menschen. Allerdings gehört das Leben, das der Mensch bereits erfahren hat oder zu erfahren im Begriff ist, zum Wirklichen, das noch nicht erfahrene Leben dagegen zur Idee. Historische Werke und Biographien sind unter den wirklichen Dingen die wirklichsten, Mythologien, ${ }^{3}$ göttliche Botschaften, ${ }^{4}$ Zaubersprüche, ${ }^{5}$ Gespenstergeschichten und andere epische Texte, deren erzählter Inhalt ${ }^{6}$ mit menschlicher Weisheit nicht ermessen werden kann, sind unter den Ideen diejenigen, die am weitesten in die Idee ragen. Man mag wohl sagen, dass das Wirkliche erfordere, bis zum äussersten in das Wirkliche hineinzugehen, dass die Idee erfordere, bis zum äussersten in die Idee hineinzugehen. Der Grund ist, dass das Wirkliche die Wahrheit ${ }^{7}$ ist und man es nicht verbiegen und zur Unwahrheit machen kann; und dass die Idee das Gestaltlose ist und man es nicht verbiegen und unter Kontrolle bekommen kann. So ist es, und wie könnte es wohl auch anders sein! So, wie ich es

イデア [< engl. idea] 意). In der Einleitung des Shōsetsu sōron heisst es mit deutlichem Bezug auf Visarion Grigor'evič Belinskij (1811-1848) (der wiederum sich indirekt auf Hegel bezieht): „Im allgemeinen existiert dort, wo eine Gestalt, eine Form ist, eine Vorstellung, eine Idee. Die Vorstellung erscheint in Abhängigkeit von der Gestalt, die Gestalt existiert in Abhängigkeit von der Vorstellung. Auf der Ebene der Existenz der Dinge spricht man von der Gestalt, die nur ist, weil es eine Vorstellung gibt, und von der Vorstellung, die nur ist, weil es eine Gestalt gibt; es ist schwer, dem einen grösseres Gewicht, dem anderen kleineres Gewicht zu geben. Spricht man aber auf der Ebene des Wesens [der Dinge] davon, so ist doch die Vorstellung das Wichtigere. Gerade weil die Vorstellung im Inneren existiert, nimmt sie nach aussen hin Gestalt an, doch existiert sie noch immer, auch wenn es keine Gestalt gibt. Die Gestalt hingegen kann auch für eine vorübergehende Zeit nicht existieren, wenn es keine Vorstellung gibt.“ (NKiBT 4: 403; analytische Synopse des „Shōsetsu sōron“ in Woldering 2015a). Ishibashi greift diesen Gedanken weiter unten anhand des Begriffes mukei no shinri 無形の真理 („gestaltlose Wahrheit“) wieder auf.

2 „Idee“ für sō 想.

3 „Mythologie“ für shin’i 神意, in meiner Übersetzung als Abkürzung für shin’i setsu 神意説 (,Erzählung vom göttlichen Willen“) gedeutet.

4 „Göttliche Botschaften“ für shintaku 神託.

5 „Zaubersprüche“ für juso 呪咀. Diese nicht nachweisbare Schreibung ist wohl ein Druckfehler oder eine orthographische Variante von juso 呪詛.

6 „Erzählter Inhalt“ für kyakushoku 脚色, womit häufiger die vom Poeten in der hier erwähnten „menschlichen Weisheit“ ersonnene Textgestalt (wörtliche Bedeutung „Fundament und Färbung“) gemeint ist. Aus logischen Gründen kann dies hier aber nicht gemeint sein.

7 „Wahrheit“ für shin 真. Ishibashi verwendet später den Begriff shinri 真理 im selben Sinn. 
mir denke, muss das Wirkliche der Poesie so unwirklich als möglich, ${ }^{8}$ muss die Idee der Poesie so weit als möglich von der Idee entfernt sein. ${ }^{9}$ Diese Worte wirken zwar äusserst seltsam, sind es aber nicht. Man möge hören, wie ich dies erkläre.

Was das Wirkliche angeht, so schweift es stets auf Irrwegen umher, die Idee läuft stets aus den kategorischen Grenzen der Wahrheit ${ }^{10}$ hinaus. Aus diesem Grund ist es weder angängig, sich in einseitiger Weise allein an das Wirkliche zu halten, noch, sich in einseitiger Weise allein an die Idee zu halten. Um wieviel mehr gilt dies im Falle des Wirklichen der Poesie, die schon keine künstlerische Schrift mehr ist, wenn man im Wirklichen aufgeht! Und um wieviel mehr gilt dies auch im Fall der Idee der Poesie, von der man nicht hoffen kann, dass sie das Seelenleben oder das Geistesleben des Menschen sei, wenn sie in der Idee aufgeht! Deswegen ist der Kernpunkt der Poesie, dass sie im Inneren eine gestaltlose Vorstellung erzeugt, welche die Schrift zum Wirklichen macht, dass sie sich in der Aussenwelt eine wahrnehmbare Gestalt nimmt und diese zu einer gestaltlosen Vorstellung umgestaltet. ${ }^{11}$ Daher soll die Poesie aus der Idee hinaustreten in das Wirkliche, soll aus dem Wirklichen hinaustreten in die Idee. Es ist ein in der Allgemeinheit verbreiteter Fehler, die Idee und das Wirkliche voneinander zu trennen und der idealistischen oder der realistischen Sparte zuzuordnen. ${ }^{12}$ Ob etwas sich aufteilt in die

8 Das Wirkliche der Poesie (die durch die Poesie geschaffene Welt) wird hier Teil eines weiter gefassten Wirklichen, das auch die Welt ausserhalb der Poesie einschliesst. Eine kleine sprachliche Inkonsistenz besteht an dieser Stelle darin, dass der sonst „das Wirkliche“ bezeichnende Begriff jitsu 実 hier adverbial im Sinne von „in der Tat“ gebraucht wird.

9 Anders formuliert lautet Ishibashis Postulat: „Die in der Literatur beschriebene Wirklichkeit muss ein Substrat (Konzentrat) der referierten Realität sein und sich voll auf diejenigen ihrer Elemente beschränen, welche die Idee verkörpern. Die in der Literatur beschriebene Idee muss so konkret und gegenständlich wie nur möglich sein.“

10 „Wahrheit“ für shinri 真理. Weiter oben verwendet Ishibashi den Begriff shin 真 im selben Sinn. Shinri steht in Futabatei Shimeis „Shōsetsu sōron“ („Allgemeine Abhandlung über den Roman“, 1886; siehe Woldering 2015a) für den Hegelschen Begriff „Idee“. Da Ishibashi die Formulierung nicht als Zitat kennzeichnet, kann nur (aber mit grosser Sicherheit) angenommen werden, dass er Futabatei zitiert.

11 „Gestaltlose Vorstellung“ für kyoshō 虚象.

12 Erneut bezieht Ishibashi sich hier auf den Disput zwischen Tsubouchi Shōyō und Mori Ōgai 森鴎外 (1862-1922). Letzterer hatte im November 1889 in Shigarami zōshi 志がらみ草紙 unter dem Titel „Ima no shoka no shōsetsuron wo yomite 今の諸家の小説論を読みて“ (Bei der Lektüre aktueller Romantheorien diverser Autoren) die realistisch-psychologische Erzählung (shinriteki shōsetsu 心理的小説) und das Prinzip des vom „Schmutz der trivialen Realität gereinigten“, abstrakten Idealismus (chūshō risō shugi 抽象的理想主義) gegenübergestellt (316-318). Mori bezog sich damit explizit auf Tsubouchi Shōyō 坪内逍遥 (1859-1935), der wegen seines Eintretens für die naturgetreue Schilderung der Beweggründe menschlichen Handelns (besonders in Shōsetsu shinzui 小説神髄, 1885/1886) als Hauptvertreter des „realistischen Flügels“ (shajitsuha 写実派) bezeichnet wurde. 
idealistische oder realistische Ausrichtung, hängt allein davon ab, ob Austreten und Eintreten der Idee und des Wirklichen zuerst oder nachfolgend geschehen. Genau dort, wo das nicht wirkliche Wirkliche und die nicht vorgestellte Idee sich im Hinausgehen und Hineingehen miteinander abstimmen, dort wird die Poesie geboren. Nehmen wir als Beispiel [den Satz] „Sehnsüchtig wartete ich auf den Gespielen“. ${ }^{13}$ Da er wirklich ist und das Wirkliche so wiedergibt wie es ist, stellt er den Geist bloss, so dass es ausserhalb des Satzes weder einen emotionalen Nachklang noch einen eleganten Geschmack ${ }^{14}$ gibt. Dies ist noch keine zur Kunst gehörige Schreibweise. Überführt man dies aber von der Idee in das Wirkliche und bringt die beiden Dinge miteinander in Einklang, etwa in dem Satz „Unter dem weit ausgebreiteten Moskitonetze schlafe ich bald, bald erhebe ich mich, und das Gedenken in meinem Busen brennt mehr noch als das Feuer, in dem Moskitos verbrannten.“ (Volkslied) ${ }^{15}$ - dann erklingen Gefühl, Geschmack und Wohlklang bei weitem mehr als im zuvor zitierten Satz. Ändert man andererseits [den Satz] „Die Flammen der Laterne trafen auf den Wind und wankten hin und her“ um in „das Laternenlicht, das im Wind mit den Augen klimpert“" ${ }^{16}$ so entsteht in der Schrift ein

13 Dies ist der Sachgehalt, auf den Ishibashi zwecks Kontrastierung das anschliessend zitierte „Volkslied“ reduziert.

14 „Emotionaler Nachklang“ für yojō 余情, „eleganter Geschmack“ für fūmi 風味. Den Begriff yojō zitiert Ishibashi aus seiner eigenen Abhandlung „Shiika no seishin oyobi yojō“ (Jan. 1890; Ishibashi 1890e), indirekt also aus Kien shiwa des Minagawa Kien 皆川淇園 (Minagawa 1771).

15 „Volkslied“ für riyō 俚謡. Die erste Hälfte des hier zitierten Volksliedes geht zurück auf das Haiku Okite mitsu nete mitsu kaya no hirosa ka na 起きて見つ寝て見つ蚊帳の広さかな („Ich stehe auf und schaue, ich lege mich hin und schaue - ach, die Weite des Moskitonetzes!“). Dieses Gedicht wurde lange der Dichterin Kaga no Chiyo 加賀千代 (1703-1775) zugeschrieben und mit dem Tod ihres Gatten in Verbindung gebracht. Dieser Interpretation zufolge hätte Kaga no Chiyo nach dem Tod des Gatten unter dem für zwei Personen gedachten Netz allein schlafen müssen und die Betonung der nun nicht mehr notwendigen Weite des Moskito-Netzes wäre verhaltener Ausdruck der Einsamkeit der Dichterin. Allerdings herrscht inzwischen die Auffassung vor, dass das Haiku von einer Prostituierten namens Ukihashi 浮橋 des Bordells Maruyama in Nagasaki stamme. Demnach habe Ukihashi vergeblich auf Freier gewartet und ihre Langeweile in dem Haiku ausgedrückt. Die zweite Hälfte des Volksliedes denotiert durch den Vergleich des „Gedenkens“ (omoi 思ひ) mit der Glut des Räucherbeckens (dessen Duft Moskitos vertreiben soll) die von der Dichterin nur konnotierte Sehnsucht (oder Langeweile). Gänzlich denotierend ist die von Ishibashi vorausgeschickte sachliche Feststellung der Sehnsucht. Ishibashi führt hier demjenigen, der das Haiku als Vorstufe zum Volkslied kennt, also zwei Stufen der Denotation vor.

16 Wortlaut: Kaze ni matataku tomoshibi 風に瞬く灯火. Die Übersetzung „mit den Augen klimpern“ folgt der Etymologie des Verbes matataku 瞬 $<(m a>m e=$ Auge; tataku = klimpern). Diese Umschreibung des instabilen Lichtes (anderwärts wiederum häufig als Metapher für flüchtiges Leben verwendet) gehört seit dem Genji monogatari (10. Jhdt.) zum metaphorischen Standardrepertoire der japanischen Literatur. Ishibashi deutet keine Quelle seines Zitates an. Ein möglicher Prototext ist das von Enami Teifu 榎並貞富 (?-1712) stammende kyōka-Gedicht Nr. 278 aus der von Asakura Kōfū 朝倉行風 kompilierten Sammlung Gosen ikyoku shū 後撰夷曲集 
Moment der Bewegung, und in ihm ist eine fein durchdachte Wirkung. Das liegt daran, dass man hier vom Wirklichen zur Idee übergegangen ist.

Ich möchte noch ein weiteres Beispiel anführen, um uns des Effektes der Harmonisierung von Idee und Wirklichem zu versichern.

Träten Tränen der Traurigkeit aus den Augen hervor, Tränen des Zornes aber aus den Ohren, so könntest du wohl ohne Worte mein Herz verstehen. Doch treten die Tränen nun einmal immer nur aus den Augen hervor. (Shigure Kotatsu). ${ }^{17}$

Den dornenreichen Weg von der Kinderwiege bis zum Friedhof gehen wir alle, ob nun am Stock oder ohne Stock, einmal bis zum Ende. (Aus der Gedichtsammlung des Mirza Schaffy, ${ }^{18}$ aus der ich im Vorworte meines bescheidenen Werkes Tsuyuko hime ${ }^{19}$ in Übersetzung zitiert habe.)

(Nachlese andersartiger Stücke, 1672). Es lautet: Fushigi ya nakaze ni matatakutomoshibi nokienu to omoebahotaru nite sōrō 不思議やな風にまたたく灯の消えぬと思へば蛍にて候 (Seihakudō/ Asakura 1929 [1672]: 200; siehe auch Kuroki 1985: 57). „Wundersam fürwahr!Im Winde klimpert mit den Augendie Laterneund kaum meint man, sie sei erloschen[stellt sich heraus,] es war ein Glühwürmchen“. Wie schon im Falle des haiku der Prostituierten Ukihashi stellt Ishibashi hier das Denotat der Trope als Kontrastmittel voran.

17 „Shigure Kotatsu“ 時雨炬燵 bezeichnet eine Szene aus dem zweiten Akt des 1720 erstmals aufgeführten jōruri-Puppentheaters Shinjū Ten no Amijima 心中天の網島 (Der LiebesDoppelselbstmord von Amijima) des Chikamatsu Monzaemon 近松門左衛門 (1653-1724). In der betreffenden Szene, aus der Ishibashi wörtlich zitiert (NKBT 49: 373), vergiesst der Protagonist Tränen, kurz nachdem er auf Drängen seiner Familie seiner Geliebten (einer Prostituierten) schriftlich abgeschworen hat und zu seiner Frau zurückgekehrt ist. Seine Frau interpretiert die Tränen zunächst als Beweis dafür, dass ihr Mann die Prostituierte noch immer liebe und Tränen der Reue über seinen Schritt vergiesse, doch dieser erklärt ihr, dass er nicht aus Trauer weine, sondern aus Wut über einen vermeintlichen Betrug seitens der Prostituierten. (Keene 1961: 407-408).

18 „Mirza Schaffy“ für Mirsä Schäfi Waseh (1792-1852), in Tbilissi (Georgien) ansässiger Dichter, bei dem Friedrich von Bodenstedt (1819-1892) im Jahre 1844 orientalische Sprachen studierte. Bodenstedt veröffentlichte 1851 unter dem Titel Lieder des Mirza Schaffy und 1887 unter dem Titel Aus dem Nachlasse des Mirza-Schaffy eigene Gedichte, die er zunächst als seine Übersetzungen von Gedichten des Mirsä Schäfi Waseh ausgab. Im Nachwort räumt Bodenstedt aber ein: „Ich zeichnete das Bild Mirza=Schaffy's, wie es vor meinem geistigen Augen stand und liess sein Wesen in den Liedern und Sprüchen sich abspiegeln, die ich ihm in den Mund legte und die zum grossen Theil in der That unter den Anregungen entstanden waren, welche ich ihm verdankte.“ (Bodenstedt 1887: 202). Ishibashi übersetzt das titellose Gedicht Nr. 10 aus Aus dem Nachlasse (Bodenstedt 1887: 52), das im Original lautet: „Den Dornpfad von der Wiege bis zum Grab/ Muss jeder gehn, ob mit, ob ohne Stab:/Die Einen unterscheiden sich von Andern / Nur durch die Art wie sie durchs Leben wandern“. Ishibashis Übersetzung ist allerdings mehr als komplett: Wird im Original die Verschiedenheit der Lebensweise wertneutral erwähnt, erweitert Ishibashi die Beschreibung um die Wertungen „gut“ und „ungut“ sowie „klug“ und „dumm“.

19 „Tsuyuko hime“: 露子姫 (Prinzessin Tautropfen, 1889 erschienene Erzählung von Ishibashi Ningetsu (Ishibashi 1889d). Ishibashi beginnt sein eigenes Vorwort zum Tsuyuko hime mit seiner 
Der erste [Text] setzt das Wirkliche der Aussage „Ich weine nicht aus Trauer, sondern aus Zorn“ um in die Idee, der zweite setzt die Idee der Aussage „Wie beschwerlich auch immer der Lebensweg sein mag, gelangen alle bis zum Tode, sobald sie nur einmal geboren sind“ um in das Wirkliche. Deswegen [sage ich]: das, wovon er spricht, mag keine tiefe Bedeutung haben, aber ist es denn nicht so, dass es mit viel Gefühl und Geschmack angereichert ist und, von nicht Ausgesprochenem überströmend, die Herzen der Menschen in Bewegung bringt? Wer also möchte da Poesie verfassen nur mithilfe der Idee? Wer möchte da Poesie verfassen nur mithilfe des Wirklichen?

\section{Gebiet des Menschen und Gebiet der Poesie}

Im unendlich weiten Lebensraum des Menschen findet sich zwar verstreut das Material des Poeten in tausendfacher und zehntausendfacher Vielfalt, so dass er es an jedem beliebigen Orte einsammeln kann, doch gibt es darunter solches, das zur Poesie gehören kann und solches, das nicht zur Poesie gehören kann. Das ist der Grund, weswegen ich zwischen dem Gebiete des Menschen und dem Gebiete der Poesie unterscheide. Sollte nun jemand ohne Wissen um den Unterschied zwischen dem Gebiet des Menschen und dem Gebiet der Poesie gedankenlos eine Schrift zusammenstellen und behaupten, es handele sich um Poesie, dann ist er, wenn schon nicht dumm, so doch in seinem Blicke oberflächlich. Ich weiche nicht unbedingt von den Ansichten der Realisten ab, und überdies erkenne ich an, dass im Schönen nicht unbedingt auch das Gute existieren muss. ${ }^{20}$ Und doch entkommen solche [Autoren]

(nicht als solche gekennzeichneten) Übersetzung des Gedichtes Nr. 10 aus Friedrich von Bodenstedts Aus dem Nachlasse des Mirza-Schaffy (s. o.). Dem ersten Kapitel von Tsuyuko hime stellt Ishibashi dann das Gedicht Nr. 10 mit Quellenangabe in Originalsprache und -schrift voran (MBgZ 23: 219), ohne seine zuvor gebotene Übersetzung damit in Verbindung zu bringen. 20 „Realisten“ für jissha ha 実写派: allgemein die Bezeichnung für die Bewegung des literarischen Realismus. Der Beginn der japanischen Diskussion des Verhältnisses zwischen ausserliterarischer (gesellschaftlicher) Wirklichkeit und Literatur wird in der Literaturgeschichtsschreibung einhellig bei der Schrift Shōsetsu shinzui 小説神髄 (1885/ 1886) von Tsubouchi Shōyō 坪内逍遥 (1859-1935) angesetzt. Als Vorform der „Erzählungen der Gegenwartsgesellschaft“ kennzeichnet Tsubouchi die „Bücher der menschlichen Gefühle“ (ninjōbon 人情本, bei Tsubouchi in der Schreibung ninjōbon 情史) des Bakin-Zeitgenossen Tamenaga Shunsui 為永春水 (1790-1843). Tamenagas Erzählungen schildern die sozialen Verhältnisse der ,untersten Gesellschaftsschicht“ (karyū shakai 下流社会) der Gegenwart (NKiBT 3: 82). Da Ishibashi im nächsten Satz Tamenaga konkret nennt, liegt die Vermutung nahe, dass Ishibashi mit dem Begriff „Realisten“ Bezug auf Tsubouchi nimmt. Doch nimmt er wohl auch auf den zwischen Iwamoto Yoshiharu 嚴本善治 (1863-1942) und Mori Ōgai ab April 1889 geführten Disput 
wie jener Tamenaga Shunsui, ${ }^{21}$ mögen ihm auch die Vorteile der Detailgenauigkeit ${ }^{22}$ nicht abgehen, schliesslich nicht der Einordnung in die Reihe der oberflächlichen Betrachter. Aber auch die älteren Werke von Meister Kōson, ${ }^{23}$ Hara no ko, Mawariguruma und Ko no tegashiwa (die allesamt in Muratake enthalten sind), ${ }^{24}$ betrachten das Gebiet der Poesie und das Gebiet

über das wünschenswerte Verhältnis zwischen Literatur und Natur (Realität, Fakten) sowie über das Schöne ( $b i$ 美) und das Gute (zen 善) in der Literatur. Iwamoto vertrat die Meinung, dass die grösste Literatur diejenige sei, welche die Natur so darstelle wie sie ist. Zudem seien in der Literatur das Gute und das Schöne untrennbar miteinander verbunden. Mori hielt Iwamoto vor, die naturgetreu abbildende wissenschaftliche Literatur nicht von der die im Gegenstand verborgene Idee herausarbeitende schönen Literatur zu trennen. Ishibashi bezieht hier, wenn auch undeutlich, Position für Moris Standpunkt in Bezug auf die Wahl des in der Literatur behandelbaren Stoffes. Die von Mori in „Bungaku to shizen“ wo yomu“ entwickelte Vorstellung einer „Idee“ (idē 想) als einer unendlichen Bedeutung, die man in endlichen Gegenständen erkenne (Idē wa yūgen no mono ni tsuite mugen no gi wo miru mono nari 想は有限の物に就いて無限の義を見るものなり。 OGZ 16: 13; vollständige Übersetzung: Woldering 2015b) greift Ishibashi auffälligerweise nicht auf.

21 „Tamenaga Shunsui“ 為永春水: Autor der späten Edo-Zeit, der in seinen ninjōbon 人情本 („Büchern menschlicher Gefühle“) das Gefühlsleben etwa einer Prostituierten und ihres Geliebten auf realistische Weise schilderte. In Shōsetsu shinzui kontrastiert Tsubouchi Shōyō die Texte dieses Autors mit den yomihon des Takizawa Bakin 滝沢馬琴 (1767-1848), wobei Tsubouchi die Protagonisten Bakins als unrealistische, überkommene Moralvorstellungen stereotyp verkörpernde Figuren kennzeichnet.

22 „Detailgenauigkeit“ für samatsu 些末. Der Ausdruck kennzeichnet sonst häufig abwertend die Trivialiät, kann hier aber nur positiv gemeint sein.

23 „Meister Kōson“ für Kōson-ō 筀村翁, respektvolle Bezeichnung des Autors und Theaterkritikers Aeba Kōson 饗庭筀村 (1855-1922). Aebas Werke sind in Stoff und Stil der Erzählprosa der Edo-Zeit verpflichtet. So ist beispielsweise Aebas Hasu ha musume (1888) eine Anlehnung an das Kōshoku Ichidai onna (1686) von Ihara Saikaku.

24 Shōsetsu Muratake 小説むら竹 (Aeba 1889-1890) ist der Titel der 1889 bis 1890 im Verlag Shun'yōdō 春陽堂 veröffentlichten Sammlung von 62 Erzählungen, die Aeba zwischen 1887 und 1890 einzeln veröffentlicht hatte. Muratake fasst in 5 Bänden 20 Einzelhefte ( $k a n$ 巻) zusammen. Ishibashi hatte beim Schreiben seiner Abhandlung offensichtlich den im März 1890 abgeschlossenen Band 3 der Sammlung vor sich. Darin enthalten sind die hier erwähnten Erzählungen Hara no $k o$ 腹の子 (Heft 13), Meguriguruma 迴り車 und Ko no tegashiwa 兒手柏 (Heft 12). Ishibashi hatte schon im August 1889 in „Kōson shi no „Muratake“筀村氏の「むら竹」（„Das “Muratake” des Herrn Kōson“; Kokumin no tomo 58; Ishibashi 1889b) vorgehalten, abgegriffene Gestaltungsmuster nach Art des Tamenaga Shunsui zu verwenden. Vernichtend aber war die zwei Monate vor dem „Sō jitsu ron“ veröffentlichte Kritik „Muratake Dai jūichi kan むら竹第十一巻“; Ishibashi 1890d). Nach einem höflich-rituellen Lobgesang auf Aebas grosse Talente wirft Ishibashi dem Autor vor, (a) Motive (shukō 趣向) zu verwenden, die man in dieser oder ähnlicher Gestalt schon allzu oft gesehen habe, (b) weit von Empfindungen (jō 情) zu sein, im Realität[sbezug] flach zu sein (jitsu ni asaku shite 実に浅くして), (c) in Idealvorstellungen flach und dünn zu sein (risō senpaku ni shite 理想浅 薄にして), (d) es an [Gestaltungs]dichte (chimitsu 緻密), überragender Schönheit (shūrei 秀麗) und Aufrichtigkeit (shinsotsu 真率) fehlen zu lassen, (e) dass die ganze Erzählungen (zenpen 全篇) umfassenden Motive und persönlichen Begebenheiten (jinji 人事) flach und abgenutzt seien. Die 
des Menschen als dasselbe, sind daher Werke, in die man mit Gewalt Dinge hinein gezwängt hat, die nicht zur Poesie gehören. Ich möchte daher zugespitzt sagen, dass derartige Werke keine Romane sind. Bezieht man zusätzlich die dritt- und viertklassigen Romanautoren ein, so reicht der Platz nicht aus, um diejenigen Werke aufzuzählen, die den besagten Schwächen erliegen. Um nun an dieser Stelle ein extremes Beispiel anzuführen: die Gestalt einer Bauersfrau, die auf dem Felde ihre Beine ungehemmt ausstreckt und Bratkartoffeln verspeist, gehört in der Tat in das Gebiet des Menschen, wohingegen die Gestalt einer Bauersfrau, die auf einem Gemüsefelde steht, zurückblickt und die ihr sehnsüchtig nachgefolgten zahmen Tauben mit Brot füttert, gehört in der Tat in das Gebiet der Poesie. ${ }^{25}$ Ich habe bislang noch nicht davon gehört, dass ein Poet in China oder Europa ein praktisches Beispiel für das Gebiet der Poesie gegeben hätte (und wenn man mit Gewalt danach sucht und sich herausstellt, dass es doch ein Beispiel gibt, so ein ausserordentlich unausgereiftes). In unserem Lande gibt es ein einzig dastehendes Beispiel, möchte ich sagen, nämlich die Poetin des Damengemaches, Sei Shōnagon. ${ }^{26}$ Sind nicht in ihrem Makura sōshi die zehn mal einhundert Beispiele, die sie unter „Was das Herz zum Klopfen bringt“, ${ }^{27}$ „Was Sehnsucht weckt, wenn es vorbei ist“, ${ }^{28}$ „Was uns zufrieden macht“, 29 „Was unangenehm ist“, 30 „Was unpassend wirkt““31 und anderem aufführt, eine feinsinnige Auswahl

wesentlichen Gründe für die Mängel seien, (1) dass Aeba die Disposition (jisupojichion ヂスポジチ ヨン) des Gesamtwerkes zu leicht nehme, (2) dass Aeba keine Schönheit (bi 美) schaffe, bei welcher er sich um Phantasie (fantaji 想) kümmere.

25 Wieder schickt Ishibashi eine „unpoetische“ Szene vorweg, um ihr sofort die „poetische“ Variante gegenüberzustellen. Für die Szenerie mit Bäuerin und Tauben konnte weder eine textuelle noch eine bildliche Vorlage ermittelt werden.

26 Sei Shōnagon 清少納言: Dienerin im Damengemach der Kaisergattin und Dichterin am Hofe der Heian-Zeit (Ende 10, Anfang 11. Jhdt.), Verfasserin der im folgenden erwähnten MiszellenSammlung Makura no sōshi 枕草子 (Das Kopfkissenbuch der Hofdame Sei Shonagon, um 1000, Sei (1000); Ishibashi gibt die Titelvariante Makura sōshi 枕州紙 an). Ishibashi zitiert im folgenden einige der Kategorien, welche die Poetin geschaffen hat, um darunter ihre persönlichen Eindrücke und Empfindungen vor allem des höfischen Lebens ihrer Zeit einzusortieren.

27 Kokoro tokimeki suru mono 心ときめきするもの: orthographische Variante des Originaltitels Kokoro tokimeki suru mono こころときめきするもの (NKBT 19: 72). Die deutschen Übersetzungen der Kategorientitel in Das Kopfkissenbuch der Hofdame Sei Shonagon (Sei/ Watanabe 1952 [1000]) sind ungenau.

28 Sugikoshi kata koishiki mono すきこしかた恋しきもの: Variante des Originaltitels Suginishi kata koishiki mono すぎにしかた恋しきもの (NKBT 19: 72).

29 Kokoro yuku mono こころゆくもの (NKBT 19: 72).

30 Nikuki mono 憎きもの: Schreibvariante des Originaltitels Nikuki mono にくきもの (NKBT 19: 68). 31 Susamajiki mono すさましきもの (NKBT 19: 64). 
dessen, was in das Gebiet der Poesie gehört? Ach, Sei Shōnagon war eine fürwahr einzigartige Meisterin!

Ich bin der Meinung, dass man, wenn man Poesie verfassen will, sein Augenmerk zunächst einmal auf zweierlei richten sollte. Das erste besteht darin, das Gebiet des Menschen und das Gebiet der Poesie genau zu ergründen. Das zweite besteht darin, das Gebiet der Poesie in künstlerischer Gestalt $^{32} \mathrm{zu}$ konzentrieren. Man sollte aber, wenn man dies unternimmt, sich einerseits das Wirkliche zum Vorbilde nehmen, sich andererseits die Idee zum Vorbilde nehmen. Der Poet Graf Platen hat einst das folgende gesagt: „Glücklich, fürwahr, ist der Poet. Der Poet bewahrt nicht nur die Gegenwart, welche die Zeit gebiert, für die Ewigkeit, er lässt auch das Gegenständliche an seinem Orte unvergänglich werden. “33 Damit hat er in besonderer Weise auf die Notwendigkeit hingewiesen, dass der Poet sich das Wirkliche zum Vorbilde nehme. Ob es nun die Ewigkeit, das Bewahren oder das Unvergängliche ist: schliesslich ist das nichts anderes als die feinsinnige Auswahl im Gebiete der Poesie. Auch Mirza Schaffy, ein Philosoph aus Tiflis im fernen Russland, ${ }^{34}$ äusserte sich dazu mit den Worten:

Dichtergenie - oh, Dichtergenie, vom Himmel verliehene Begabung! Du legst den Boden des menschlichen Lebens aus mit duftenden Blüten, entnimmst aus der Freude Watte, gewinnst aus dem Leiden Arzenei, und, um das Wiederspiegeln der Klarheit ${ }^{35}$ aus dem alten Brunnen des Lichtes und der Wahrheit hervorzurufen, führst du einen goldenen Strahl vom Himmel in das Herz. ${ }^{36}$

32 „Künstlerische Gestalt“ für bijutsu-teki no shōkei 美術的の象形.

33 Das auf den 2. August 1829 datierte Epigramm des August von Platen (1796-1835) ist unter der Überschrift „Dichtergeschick“ enthalten in Epigramme (1847) und lautet „Selig der Dichter, er kann festhalten das zeitliche Dasein, aber verewigen auch alle Gestalten des Raums!“ (Platen-Hallermünde 1847-2: 268). Da Ishibashi im übernächsten Satz auf Wörter aus seiner eigenen Übersetzung Bezug nimmt, musste ihr hier der Vorzug vor dem Platenschen Original gegeben werden.

34 „Tiflis“ (amtlich „Tbilissi“, heutige Hauptstadt Georgiens) gehörte von 1801 bis 1917 zum russischen Zarenreich.

35 Den Begriff „Klarheit“ verschriftet Ishibashi hier nach dem oben beschriebenen Muster kurāruhaito 明解 [meikai].

36 Das von Ishibashi übersetzte (in Wahrheit von Bodenstedt und nicht von Mirza Schaffy verfasste) titellose Gedicht Nr. 57 aus Aus dem Nachlasse des Mirza-Schaffy lautet: „O Geist der Dichtung, göttliche Gabe, du / Deckst mit Blumen den Abgrund des Lebens zu;Du beutst Weihe der Freude und Balsam dem Schmerz / Ziehst goldne Fäden vom Himmel ins HerzAuf dass schon hienieden ein Abglanz der Klarheit / Uns werde vom Urborn des Lichts und der Wahrheit.“ (Bodenstedt 1887: 69). Ishibashi hat offensichtlich das von Bodenstedt im Sinne von „bieten“ verwendete Verb „beuten“ gar nicht, das im Sinne von „Heiligung“ verwendete Wort „Weihe“ (Deutsches Wörterbuch von Jacob Grimm und Wilhelm Grimm, Leipzig 1854-1960, 
Damit hat er in besonderer Weise die Notwendigkeit hervorgehoben, dass der Poet sich die Idee zum Vorbild nehme. Ob es die Blüten sind, ob die Watte, ob es die Arzenei ist, ob das Licht, ob es die Wahrheit ist, ob ein goldener Strahl - es bedeutet nichts anderes, als das Gebiet der Poesie in künstlerischer Weise zu konzentrieren. Mit einem Worte: die Dichtung erreicht letztendlich nicht das Gebiet der Poesie, wenn sie sich für ihren Gegenstand nicht das Wirkliche zum Vorbild nimmt, und wenn sie sich nicht die Idee zum Vorbild nimmt, so kann das Gebiet der Poesie wiederum nicht zum „Schönen“ gehören. ${ }^{37}$ Wenn nun aber die Idee sich nicht auf das Wirkliche verlässt, so ist sie schliesslich haltlos oder leer. $^{38}$ Wenn andererseits das Wirkliche sich nicht auf die Idee verlässt, so kehrt es sich schliesslich um in das Gebiet des Menschen.

\section{Ewiges und Unvergängliches}

Es ist die erlesene Kunst des Poeten, die Phänomene des menschlichen Lebens hin- und herzuwenden, genau in Augenschein $\mathrm{zu}$ nehmen, ausserhab des Phänomens die gestaltlose Wahrheit ${ }^{39} \mathrm{zu}$ erfassen und womöglich eine Welt widerscheinen $\mathrm{zu}$ lassen, die um eine Stufe weiter fortgeschritten ist als die Phänomene. Unreif in der Poesie ist derjenige, der das Gestaltlose nicht im gestalthaften Phänomen sucht, der das Hohe und Weite nicht in den niederen, erdnahen menschlichen Empfindungen aufspürt. Der Unreifste unter den Unreifen ist derjenige, der das Gestalthafte nicht in der gestaltlosen Wahrheit widerscheinen lässt, der das Niedrige und Erdnahe nicht in hohe und weite Entwürfe $^{40}$ überträgt. Der grosse Poet hat für gewöhnlich das Auge, das um eine Stufe über seine Gegenwart hinausgeht; beim kleinen Poeten aber ist das Gegenteil der Fall. Der grosse Poet fürchtet nicht den Zorn seiner Altvorderen, vielmehr graut es ihm vor dem Gelächter der Nachwelt; beim kleinen Poeten aber ist das Gegenteil der Fall. Der grosse Poet bedenkt die Ereignisse, macht

s.v. beuten, Weihe) falsch verstanden und mit „Watte“ (mawata 真綿) übersetzt, weil er es wie „Arzenei“ („Balsam“) als einen aus der Medizin entliehenen Ausdruck zur Verbildlichung des Begriffes „Trost“ interpretiert. Darüberhinaus hat Ishibashi die in der Bodenstedtschen Übersetzung durch „schon hienieden“ implizierte Jenseitsvorstellung nicht umgesetzt.

37 Hier bezeichnet das Wort „Poesie“ (shi 詩) Texte, die in das „Gebiet der Poesie“ (shikyō 詩境) gehören. Mit „Schönes“ (bi 美) meint Ishibashi „schöne Künste“ (bijutsu 美術), in die nur Texte gehören, die im „Gebiet der Poesie“ liegen.

38 „Haltlose Idee“ für mōsō 妄想 („Wahnidee“), „leere Idee“ für kūsō 空想 („Phantasterei“).

39 „Gestaltlose Wahrheit“ für mukei no shinri 無形の真理. Zuvor hat Ishibashi den Ausdruck kyoshō 虚象 („gestaltlose Vorstellung“) verwendet, um den selben Gedanken auszudrücken. 40 „Entwurf“ für ishō 意匠. 
sich Gedanken über die Dinge und versteht es, deren geheimnisvolle Tiefe widerscheinen zu lassen; beim kleinen Poeten aber ist das Gegenteil der Fall. Mit einem Worte: der kleine Poet trachtet danach, die gewöhnliche Freude eines Augenblickes für sich in Anspruch zu nehmen, ist willkürlich und wankelmütig, liebt es, düstere und grelle Farben aufzutragen und bemerkt nicht, wie flach und seicht er im Prinzip ${ }^{41}$ ist. Der grosse Poet trachtet danach, an allen Orten der Erde und $\mathrm{zu}$ allen Zeiten gelesen $\mathrm{zu}$ werden und ist darum bemüht, Texte genialen Geistes hervorzubringen, die dem Ewigen entsprechen und es durchschreiten. Aus diesem Grunde bewirken die Werke des grossen Poeten, dass ihre Leser nicht anders können, als sie drei mal zu bedenken. Die Werke des kleinen Poeten mögen beim allerersten Anblicke noch Freude machen, doch rufen sie nach einiger Zeit Überdruss hervor. Das eine wird dem Philosophen zur Quelle der Gedanken, das andere endet als Spielzeug des gewöhnlichen Menschen. ${ }^{42}$ Oberbreyer ${ }^{43}$ hat einst die Charakterbilder des Theophrast ${ }^{44}$ kommentiert und gesagt: „Die Eigenheiten, die Herr Theophrastus abgebildet hat, sind schlechte und gute Menschen ${ }^{45}$ seiner Gegenwart. Man hat in diesem Buche also Portraits von Menschen gezeichnet, die in der Tat vor über zweitausend und zweihundert Jahren existiert haben. Doch breite ich diese Portraits vor meinem Auge aus, so sehe ich darin exakte Abbildungen unserer selbst - ist es nicht eine Überraschung, die ich da erlebe? Erblicken wir darin nicht die Gestalt der Freunde und Feinde, die unsere Zeitgenossen sind? Welchen Grund hat nun aber diese vollständige Übereinstimmung zwischen jenen Jahrtausende alten Menschen und uns, die uns so überraschen mag? Wohl nicht den, dass Herr Theophrastus schlechte und gute Menschen einzig abgebildet hätte. Es liegt daran, dass er durch die Haut drang, das Innere erreichte und so das Charakteristische der Menschheit herausarbeitete, dass er sie zwar die Maske schlechter und guter Menschen aufsetzen liess, aber nicht nach Landessitten, Alter, Mann oder Frau und nach Beruf fragte. Sitte und Klima der verschiedenen

41 „Prinzip“ für $r i$ 理.

42 Die hier entwickelte Vorstellung von der Kunst als Quelle der sich entwickelnden philosophischen Vernunftidee lässt erneut den Hegelschen Gedanken von der Schönheit als Präsenz der Vernunftidee (Gethmann-Siefert 2005: 54-56) anklingen.

43 Max Oberbreyer (1851-1918) hat neben seinen Tätigkeiten als Schriftsteller, Journalist und Feuilletonist zahlreiche lateinische und griechische Klassiker übersetzt und kommentiert.

44 „Theophrast“: 372-287 a.Chr. n. Sein um 319 v. Chr. verfasstes Werk Charaktēres (auch Ethikoi charakteres) enthält 30 Definitionsskizzen zu Charakterzügen des Menschen (z. B. „Überheblichkeit“, „Feigheit“).

45 „Schlechte und gute Menschen“ für azenjin 亜善人, worin $a$ 亜 als Synonym für $o$ 悪 fungiert. 
Länder üben wohl Einfluss auf das Äussere des Menschen aus, doch ihr Herz und ihr Empfinden werden sicherlich zu keiner Zeit und an keinem Orte davon bewegt. Was sie trennt, sind alleine Zeit und Raum, im Geiste aber gibt es zwischen ihnen keinen Abstand. Es gibt zwischen dort und hier einen Unterschied in der Sprache, nicht aber einen Unterschied in Denken und Vorstellung. Es gibt einen Unterschied in den Sitten, nicht aber einen Unterschied im Handeln. “46 So hat er gesprochen. (Für Obiges ziehe man die Zweitübersetzung „Verschiedene Menschen“ des Meisters Jishō ${ }^{47}$ zurate.) Wahrhaftig, der Grund dafür, dass das Buch Charakterbilder den ehrenvollen

46 Im Original lautet die von Ishibashi zitierte, von Nishimori Takeki (Nishimori 1888) etwas ungenau übersetzte Textstelle aus Oberbreyers „Einleitung“: „Diejenigen nämlich, deren Sitten uns Theophrast in seinen Charakterbildern malt, waren doch seine Zeitgenossen, die Athener, und seit der Zeit, da er von diesem Volke von Athen Schilderungen entworfen, sind bis heute 22 Jahrhunderte verflossen: und doch - wenn wir jetzt diese Zeichnungen vor Augen halten, müssen wir nicht mit Staunen unser eigenes Porträt darin erkennen? Werden wir nicht die Züge auch unserer Zeitgenossen, unserer Freunde und Feinde in ihnen sehen? Woher diese überraschende, so vollständige Aehnlichkeit mit Menschen, die durch so viele Jahrhunderte von uns geschieden sind? Nun, der griechische Philosoph hat hier eben nicht nur Athener skizzirt, er ist durch die Schale auf den Kern gedrungen und hat, nur unter der Maske des Atheners, den Menschen gezeichnet, den Menschen allein ohne Rücksicht auf Nationalität, Alter, Geschlecht, Beruf. So bestätigt sich auch hier die Wahrheit des alten Erfahrungssatzes, dass wohl Klima und Sitten eines Landes die Menschen im Aeussern beeinflussen können, dass sie aber im Grunde nach Herz und Leidenschaften sich alle gleich bleiben - zu jeder Zeit und unter jeder Zone. Was Jene und uns trennt sind nur zeitliche und örtliche, nicht geistige Abstände; nur Unterschiede der Sprache, nicht der Gedanken; nur Ungleichheiten der Sitten, nicht der Handlungen.“ (Oberbreyer 1874: 5-6).

47 „Meister Jishō“ (Jishō shi 自笑子) ist das Pseudonym des Nishimori Takeki 西森武城 (18621913). Bekannt war Nishimori bereits 1888 durch die Veröffentlichung satirischer Charakterschilderungen von Japanern unter dem Titel Hyakunin hyakuiro 百人百色 (Ukiyo shashin 浮世写真) (Hundert Menschen, hundert Farben - Fotografien unserer Welt; Nishimori 1888). Das Frontispiz zeigte Nishimori als Fotografen, der mit seiner Kamera in eine japanische Menschenmenge hineinphtographiert. Es folgten dann Schilderungen etwa des typischen Quacksalbers (yabu isha), eines Mannes, der durch die Meiji-Restauration seinen privilegierten Samurai-Status eingebüsst hatte ( $k y \bar{u}$ samurai), des traditionellen China-Gelehrten (kangaku sha) und des modernen West-Gelehrten (yōgaku sha). Die Zweitübersetzung der Charaktēres von Theophrast veröffentlichte Nishimori zuerst in 26 Folgen unter dem Titel Hito samazama 人 さまざま (Verschiedene Menschen) vom 8. Juni bis zum 31. August $1889 \mathrm{im}$ Anhang (bessatsu, furoku S1; Nishimori 1889) der Morgenausgabe der Yomiuri shinbun. Folge 1 enthält die Übersetzung von Oberbreyers Vorwort. Ishibashi zitiert diesen Text mit kleinen orthographischen Abweichungen. 1892 erschien Nishimoris Übersetzung unter dem selben Titel als Monographie im Verlag Seikandō 精完堂. 
Namen „Goldenes Büchlein“ erhielt, dürfte wohl hierin liegen. ${ }^{48}$ Wenn ein Poet diese kritischen Worte stets beherzigt, sich deren Sinn zueigen macht und ihn nicht vergisst, so wird seine Poesie über alle Zeiten hinweg hochgeschätzt werden und sicherlich nicht in einer Zeit vergehen. Deswegen meine ich stets, dass die Poesie das Ewige und Unvergängliche hochschätzt. Trachtet man danach, sie zu etwas Ewigem und Unvergänglichen werden zu lassen, so sollte man zum einen das Gestaltlose im gestalthaften Phänomen aufsuchen, das Hohe und Weite im niedrigen und erdnahen Empfinden des Menschen aufspüren, und man sollte zum anderen das Gestalthafte mit der Wahrheit des Gestaltlosen erleuchten, das Niedrige und Erdnahe in hohe und weite Entwürfe überführen. Diese Betätigung ${ }^{49}$ beschreibe ich als „Ausrichtung an der Idee bei Ausrichtung am Wirklichen“. Das Ewige und Unvergängliche bei Theophrastus liegt an nichts anderem als am kunstvollen Umgange mit der Idee und mit dem Wirklichen. Aus diesem Grunde also sage ich, dass die Ausrichtung des Poeten an der Idee und die Ausrichtung am Wirklichen die Voraussetzungen für das Stadium der Ewigkeit und der Unvergänglichkeit sind.

48 Max Oberbreyer übernimmt die Hymne auf ,attischen Geschmack und griechische Eleganz" sowie das epitheton ornans livre d'or (Oberbreyer 1874: 5) von Jean de La Bruyère (1645-96) aus dessen Vorwort (Discourse sur Théophraste) zu Les Caractères de Théophraste traduits du grec avec Les Caractères ou les mœurs de ce siècle (1688) (La Bruyère 1886: 6) und übersetzt livre d'or in „goldenes Büchlein“ (Ishibashi von dort aus in ōgon shōsatsu 黄金小冊). Ishibashi hat seine an Oberbreyer 1874 festgemachten Anschauungen bereits am 22. Juni 1889 in der Zeitschrift Kokumin no tomo in seinem Beitrag „Yomiuri shinbun Hito samazama 読売新聞人さまざま“ (Hito samazama in der Yomiuri shinbun; Ishibashi 1890f) kundgetan. Darin schilderte er grob Anlage und Gehalt der Charaktēres und zitierte wörtlich Teile von Nishimoris Übersetzung des Oberbreyerschen Vorwortes. Seine wesentlichen Gedanken und das Nishimori-Zitat daraus greift er ohne Rückverweis erneut auf, wohl, weil in jenem Beitrag auch das kompromittierende Eingeständnis, dass er damals die Oberbreyersche Vorlage gar nicht und Nishimoris Übersetzung nur teilweise kannte, enthalten ist.

49 Den Begriff „Betätigung“ verschriftet Ishibashi nach dem schon beschriebenen Muster betēchigungu 働作 [dōsa]. Prototext ist erneut $\S 19$ aus Deutsche Poetik (1879) von Werner Hahn, wo es im Original unmittelbar nach der in Fussnote 79 zitierten Passage heisst: „Sie stehen in innerem Zusammenhang ,mit ihren Vorstufen' d.i. mit dem leiblichen Organismus des Menschen; namentlich unmittelbar mit dessen zwei allgemeinen Bethätigungen: mit der durch die Sinne (Auge, Ohr etc.) bewirkten Bethätigung nach aussen; und mit der durch Nerven und Blut vermittelten Bethätigung im Körper selbst.“ (Hahn 1879: 43). 


\section{Grösse $^{50}$}

Trachtet man danach, ewig und unvergänglich zu sein, so muss man erkennen, was dichterische Grösse ${ }^{51}$ eigentlich ist. Das Ewige und Unvergängliche geht sicherlich mit Grösse einher und ist niemals davon getrennt. Ich meine, dass es bei der Grösse ${ }^{52}$ zwei Arten gibt, nämlich zum einen diejenige, die ich als Grösse des Äusseren bezeichne, zum anderen diejenige, die ich als die Grösse des Inneren bezeichne. Grösse des Äusseren beschränkt sich darauf, die Oberfläche der Poesie gross zu gestalten, Grösse des Inneren macht allein das Wesen gross. ${ }^{53}$ Mag die Oberfläche auch noch so gross sein - wenn das Wesen nicht gross ist, so ist [die Poesie] im Nutzen so unterlegen wie im allgemeinen ein grosser Angelika-Baum gegenüber einem Paternosterbäumchen von nur einem Sun Höhe. ${ }^{54}$ Wenn aber demgegenüber das Wesen [der Poesie] gross ist, dann möchte ich sie preisen als etwas, woran man dichterische Grösse erkennt, und mag ihre Oberfläche auch klein sein. Wenn jemand wiedergibt, wie Berge und Felsen zerbersten, wie Drachen und Tiger miteinander kämpfen, so ist das für sich genommen zwar gross, doch bedeutet das nichts weiter als die äussere Anlage der Poesie gross zu machen, und es heisst nicht, das Herz der Poesie ${ }^{55}$ gross zu machen. Wenn etwas aber vom Herzen der Poesie her nicht gross ist, so kann man es von vorneherein nicht als ein grosses

50 Dieser Abschnitt erschien zuvor als selbständiger Artikel unter dem Titel „Dai 大“ in der Zeitung Kōko shinbun am 5. April 1890 (Ishibashi 1890a).

51 „Poetische Grösse“ für shidai 詩大.

52 Den Begriff „Grösse“ verschriftet Ishibashi, nachdem er ihn in der Überschrift und im Text bislang mit dai 大 wiedergegeben hat, hier nach dem schon beschriebenen Muster mit gurēse 大 [dai] (> deutsch „Grösse“).

53 „Wesen“ für seishin 精神.

54 Der bis etwa zwei Meter hohe „grosse Angelika-Baum“ (botan. Aralia cordata, japan. udo no taiboku 独活の大木, wörtlich „der für sich selbst lebende grosse Baum“) wird hier als Sinnbild der Nutzlosigkeit eingesetzt: der Wildwuchs seiner Stämme macht ihn unkontrollierbar, er besteht zu 95\% aus Wasser (enthält also keine Nährstoffe) und ist ausserdem für Nutzholz zu weich. Demgegenüber ist das Holz des kleinen „Paternosterbaums“ (botan. Melia azedarach, japan. sendan 梅檀) vielseitig verwendbar (etwa für Rüstungen und Arzneien). Selbst ein junger Paternosterbaum von nur 1 „sun“ 寸 (ca. $3 \mathrm{~cm}$ ) Höhe wird deswegen in Japan traditionell sehr geschätzt. Darüber hinaus verströmt der Paternosterbaum schon in seiner Jugend seinen angenehmen Duft und steht deswegen im Sprichwort Sendan futaba yori kōbashi („Ein Paternosterbaum duftet, sobald seine Blätter sich teilen“) sinnbildlich für ein früh aufkeimendes grosses Talent. Wegen beider Eigenschaften wird der Paternosterbaum hier als Sinnbild der Nützlichkeit eingesetzt.

55 „Herz der Poesie“ für shishin 詩心. 
Schriftwerk von literarischem Werte ${ }^{56}$ bezeichnen. Freilich: Kinder, Frauen und gemeine Menschen ${ }^{57}$ mögen die Aufzeichnungen von der Strandung des Robinson ${ }^{58}$ und das Shintō Suikoden lesen $^{59}$ und diese Werke als angenehm oder absolut einzigartig loben, und da sie Poesie geradeso wie ein Spielzeug betrachten, kann man ihnen darum keine tiefgehenden Vorwürfe machen. Und mögen die persönlichen Angelegenheiten und die persönlichen Begebenheiten, ${ }^{60}$ die [diese Werke] wiedergeben, auch gering erscheinen, mögen in ihnen müssiggängerische Mutwilligkeiten in abgelegenen Gefilden enthalten ist, ${ }^{61}$ mag es darin um nicht mehr gehen als um die Liebeslust einfacher Männer und Frauen, ${ }^{62}$ so sind sie doch im Geiste, im Herzen der

56 „Literatur“ für bungaku 文学. Notabene: bis hierher hat Ishibashi den allgemeinen Begriff „Schriftwerk“ (monji 文字) verwendet.

57 „Kinder, Frauen und gemeine Menschen“ für jijo bon'yō 児女凡庸.

58 Der Robinson-Stoff war in Japan seit der späten Edo-Zeit sehr populär und Gegenstand zahlreicher Bearbeitungen. Das Feld der in Frage kommenden Prototexte lässt sich daher nur ungefähr abstecken. Ishibashi nennt als Titel Robinson hyōryū ki ロビンソン漂流記 (Aufzeichnungen von der Strandung des Robinson). Zu den frühesten japanischen Übersetzungen des Defoeschen Romans (The Life and Strange Surprizing Adventures of Robinson Crusoe of York, Mariner, 1719) zählt das Robinson hyōkō kiryaku 魯敏遜漂行紀略 (Kurze Aufzeichnungen von der Strandung des Robinson, 1857) von Yokoyama Yoshikiyo 横山由清 (1826-1879). Zwischen Yokoyamas Übersetzung und Ishibashis Schreibgegenwart (1890) erschienen mehrere Bearbeitungen mit Titeln, die mit dem von Ishibashi genannten teilweise oder ganz übereinstimmen. Nimmt man die Titelangabe des allerdings häufig ungenau zitierenden Ishibashi einmal ernst, kommen als Prototext das Robinson hyōryū ki 魯敏孫漂流記 (Inoue 1883) des Inoue Tsutomu 井上勉 (1850-1905) und das Robinson hyōryū ki 魯敏孫漂流記 (Ushiyama 1887) von Ushiyama Kakudō 牛山鶴堂 und Atobe Sozan 跡部素 山 (Lebensdaten in beiden Fällen unbekannt) in Frage.

59 „Shintō Suikoden“: Kurztitel des Shunketsu Shintō Suikoden 俊傑神稲水㶆伝 (HeldengötterShuihu zhuan, 1828-1882), ein auf chinesischen Vorlagen beruhender, hinsichtlich der Anzahl handelnder Personen und Textmenge von 140 Heften in 128 Bänden monumentaler yomihonAbenteuerroman, verfasst von Gakutei Kyūzan 岳亭丘山 (Lebensdaten unbekannt) (Bde. 1-4) und Chisokukan Shōkyoku 知足館松旭 (Lebensdaten unbekannt) (Bde. 5-128) (Gakutei/ Chisokukan 1898 [1828-1882]). Notabene: Ishibashi bezieht sich auf einen der Erzähltradition der späten Edo-Zeit verpflichteten Abenteuerroman, dessen letztes Kapitel nur sieben Jahre vor dem „Sō jitsu ron“ erschien.

60 Vorausdeutung auf den folgenden Abschnitt.

61 Ishibashi meint die kleinen und langsamen Schritte des auf einer abgelegenen Insel lebenden Robinson hin zu einem zivilisierten Leben.

62 Ein Beispiel für die von Ishibashi wohl gemeinten Liebesgeschichten einfacher Männer und Frauen im Shunketsu Shintō Suikoden ist Kapitel 2 in Band 2. Der tugendhafte Räuberhauptmann Akushirō Takamasa hat den Verbrecher Kongō Jirō geschlagen und fordert nun das als Geisel im Versteck lebende Mädchen Koshiba auf, sich zu entleiben. Sie sei die Geliebte ihres Entführers Kongō Jirō geworden und habe damit ihre jungfräuliche Reinheit verloren. Das Mädchen bittet um ihrer in einem abgelegenen Dorf lebenden Eltern willen um Gnade, wovon Takamasa sich gerührt zeigt. Da sie ein einfaches „Mädchen vom Lande (domin no musume)“ sei, begnadigt er 
Poesie gross und haben in der Tat den Sinn der Poesie erfasst. Sie gehören zur höchsten Poesie. ${ }^{63}$ Erzählungen wie das Kajin no kigū des Shiba Tōkai, ${ }^{64}$ wie das Setchūbai des Suehiro Tetchō ${ }^{65}$ und wie das Hōchi ibun des Yano Ryūkei ${ }^{66}$

sie nicht nur, sondern schickt sie unter der Bedingung absoluter Verschwiegenheit mit dem gesamten ihr geraubten Geld zurück in ihr Heimatdorf, damit sie ihren Verlobten Yosanda heirate. So geschieht es schliesslich auch (Gakutei-Chisokukan 1898 [1828-1882] 44: 16-19).

63 Die Robinson-Bearbeitungen von Inoue und Ushiyama sind weniger in der Textmenge als vielmehr in der räumlichen Ausdehnung der Handlung gross angelegt. Beim Shintō Suikoden verhält es sich umgekehrt. Ishibashi meint demnach, dass auch in der räumlichen Ausdehnung der Handlung oder in der Textmenge gross angelegte literarische Werke die von ihm postulierte innere Grösse enthalten können und bereitet damit die Kontrastierung mit den ebenfalls gross angelegten, im folgenden genannten politischen Romane Kajin no kigū, Setchūbai und Hōchi ibun vor.

64 Kajin no kigū 佳人之奇遇 (Wundersame Begegnung schöner Menschen): In 10 Bänden von 1885 bis 1897 veröffentlichter Fortsetzungsroman des Shiba Shirō 柴四郎 (1852-1922; Pseudonym Tōkai sanshi 東海散士), der in puncto Monumentalität den zuvor genannten Titeln Robinson und Shunketsu nicht nachsteht (Shiba 1885-1897). Dies gilt auch für die im folgenden genannten Titel Setchūbai und Hōchi ibun. Der an sich schon umfangreiche Haupttext jedes Bandes des Kajin no kigū ist in ein aufwendig gestaltetes Ensemble aus Vor- und Nachworten eingebettet. Die Exposition schildert das Zusammentreffen politischer Flüchtlinge verschiedener Länder auf dem Turm der Freiheitsglocke von Philadelphia. Man kommt ins Gespräch über das Streben nach Wiedererlangung der Freiheit in den Heimatländern. Von dort aus verzweigt sich die Erzählung in Gespräche und komplexe, locker zusammengefügte Handlungsstränge einzelner Protagonisten. Kajin no kigū ist ein herausragendes Werk des Genres „politischer Roman“ (seiji shōsetsu 政治小説), büsste aber wegen struktureller Mängel (etwa wegen der unmotiviert wirkenden Einführung autobiographischer Elemente) und der bevorzugten Behandlung der abstrakten politischen Geschichte Europas und Amerikas vor der in den Hintergrund tretenden konkreten Handlung der Protagonisten an Interesse unter der Leserschaft ein und blieb unvollendet. Ishibashis Kritik fällt mitten in die Entstehungszeit des Romans und hat womöglich zu dessen kommerziellem Misserfolg beigetragen.

65 Setchūbai 雪中梅 (Pflaumenblüten im Schnee) von Suehiro Tetchō 末広鉄腸 (1849-1896) erschien 1887 in 2 Bänden zu je 7 Kapiteln (Suehiro 1887). Die Exposition des Romans beschreibt, wie im Jahr 173 (!) der Regierung des Meiji-Kaisers anlässlich der Gedenkfeier zur Einrichtung des Parlamentes ein Denkmal für Kuninomoto ausgegraben, seine Verdienste um die parlamentarische Demokratie rekonstruiert und seine „Setchūbai“ betitelte Biographie entdeckt werden. Wie das zuvor erwähnte Kajin no kigū gilt auch das Setchūbai als repräsentativ für das Genre des „politischen Romans“. Die Protagonisten sind hier schon anhand ihrer Namen als Allegorien bestimmter Haltungen erkennbar, etwa der für Freiheit und Volksrechte eintretende Protagonist, dessen Name „Kuninomoto 国野基“ wörtlich „Grundstein des Landes“ bedeutet.

66 Hōchi ibun 報知異聞 (Unerhörtes aus dem Hause der [Zeitung] Hōchi) ist der ursprüngliche Titel des Romans, den Yano Ryūkei 矢野龍渓 (1850-1931) im März 1890 in 63 Kapiteln veröffentlichte. Im April erschien der Roman unter dem Titel Ukishiro monogatari 浮城物語 (Erzählung von einer schwimmenden Burg; Yano 1890), der ursprüngliche Titel wurde zum Titelvorsatz (tsunogaki 角書). Die Protagonisten kapern ein Piratenschiff, mit dem sie nach 
hingegen sind alle miteinander Erzeugnisse des Unwissens darum, was dichterische Grösse ausmacht. Deren Autoren sind ganz und gar von der Grösse der Oberfläche $^{67}$ fasziniert und geben nicht acht darauf, wie es um das Wesen steht. Aus diesem Grunde sind ihre Schriftwerke zeitgebunden und vergänglich, sie können nicht ewig und unvergänglich sein. Bei Werken wie den kurzen Liedern eines Goethe ${ }^{68}$ oder den haikai eines Bashō ${ }^{69}$ sind die darin angesprochenen Tatsachen gewöhnlich und unbedeutend, weswegen man daran beim ersten Blicke von der Oberfläche $^{70}$ aus keinerlei Besonderheit feststellen mag, und doch erweist sich, wenn man ihre Rückseite $^{71}$ sorgsam prüft, dass in ihnen besondere Grösse im Wesen sowie in Empfinden und Denken ${ }^{72}$ ruht. Deswegen rufen sie auch bei beständig wiederholter Rezitation nicht im mindesten Überdruss hervor. Ich preise Werke von derartiger Grösse des dichterischen Herzens und bezeichne sie als grossartige Schriftwerke, geeignet, die gesellschaftliche Situation zu befrieden. ${ }^{73}$ In jüngster Zeit stellen jene, die über die Poesie diskutieren, immer

Indonesien fahren und dort politisch agieren. Wie schon in Suehiros Setchūbai (s. o.) verweisen auch hier die Namen der Protagonisten auf deren allegorischen Charakter. So heisst etwa der Protagonist, der im Roman für zivile Gelehrsamkeit eintritt, „Sakura Gibun 作良義文“, worin „Sakura 作良“ (> sakura 桜, „Kirschblüten“) und „bun 文“ (,Text“) traditionell auf das Schriftgelehrtentum, „Gi 義“ („Pflichttreue“) auf die Tugendhaftigkeit deuten. Entsprechend heisst der Protagonist, der für militärisches Geschick und Siegeswillen steht, „Tachibana Shōbu“ (etwa „Sieg der Mandarinenorange“). Ishibashi kritisiert die Romane Kajin no kigū, Setchūbai und Hōchi ibun hier für ihr vermeintliches Missverhältnis zwischen grosser äusserer Anlage und unterentwickeltem Wesen (seishin 精神).

67 „Grösse der Oberfläche“ für hisō no gurēse 皮相の大. Gemeint sind damit die räumliche Ausdehnung der Handlung und die Textmenge.

68 Johann Wolfgang von Goethe (1749-1832). Welche Gedichte mit „kurze Lieder“ (tangin 短吟) gemeint sind, bleibt offen.

69 Matsuo Bashō 松尾芭蕉 (1644-1694), der wohl berühmteste Dichter des haikai 俳諧, einer possenhaften Variante des haiku, die wie jenes aus nur drei Versen zu 5, 7 und 5 Moren Länge besteht und auf engstem Raum komplexe Gegenstände pointenreich einfängt.

70 Die „Oberfläche“ wird hier mit hyōmen 表面 bezeichnet, nicht wie zuvor mit dem häufig abwertend verwendeten Wort hisō 皮相.

71 „Rückseite“ für rimen 裏面.

72 Das Verhältnis des „Wesens“ (seishin 精神) zu „Empfindung und Gedanken“ (kannen 感念) zitiert Ishibashi hier aus Abschnitt 2, wo er es wiederum aus der poetologischen Schrift Kien shiwa (1771) von Minagawa Kien (Minagawa 1771) zitiert.

73 „Befriedung der gesellschaftlichen Situation“ für keisei 経世. Ishibashi bezieht sich hier auf die von Aufklärern der frühen Meiji-Zeit (allen voran Fukuzawa Yukichi und Nakamura Masanao) formulierte Kritik an dem vermeintlich geringen gesellschaftlichen Nutzen der Literatur (siehe hierzu Schamoni 1975) und hält dieser Kritik sein Urteil entgegen. Dabei verwendet er den traditionellen Ausdruck keisei, der als Abkürzung für keiseika 経世家 („Mann der Befriedung der gesellschaftlichen Situation“) diejenigen Intellektuellen der Edo- 
wieder Forderungen an die Poeten. Sie sagen: „Seid grossartig!“ Sie sagen: „Seid mutig und gross!“ Sie sagen: „Seid erhaben und gross!“ 74 Es ist wahrlich

Zeit bezeichnete, die abseits der politischen Machtstrukturen konkrete Massnahmen zur „Befriedung der Welt“ (keisei) und der „Rettung des Volkes“ (saimin 済民) erarbeiteten. Den Abstand zu Strukturen politischer Macht haben die von Ishibashi favorisierten Poeten mit den keiseika gemein.

74 Alle drei Begriffe (idai 偉大, yūdai 雄大 und kōdai 高大) enthalten den in diesem Abschnitt zentralen Bestandteil dai 大. Wahrscheinlich bezieht Ishibashi sich damit auf jenen literaturtheoretischen Disput, den Iwamoto Yoshiharu 嚴本善治 (1863-1942) mit seinem Text „Bungaku to shizen 文学と自然 (Literatur und Natur) auslöste. Kernthema des Disputes wurde hiernach das Verhältnis von Literatur und Natur. Iwamoto veröffentlichte seine Theorie in Nr. 159 der Jogaku zasshi (Iwamoto 1889) und kennzeichnet dabei im Titelvorsatz „Kokumin no tomo dai-yonjūhachi gō 国民之友第四十八号“ (Kokumin no tomo Nummer 48, März 1889), dass er sich auf die in dieser Nummer enthaltenen Beiträge „Konnichi no bungakusha 今日の文学者“ (Die heutigen Literaten, Verf. Morita Shiken 森田思軒, 1861-97; Morita 1889), „Genron no fujiyū to bungaku no hattatsu 言” 論の不自由と文学の発達“ (Die Unfreiheit der Rede und die Entwicklung der Literatur, Verf. Tokutomi Sohō 徳富蘇峰, 1863-1957; Tokutomi 1889) sowie „Jiji shinpō to Jogaku zasshi ni shissu 時事新報と女学雑誌に質す“ (Was ich der Jiji shinpō und der Jogaku zasshi vorzuwerfen habe, Verf. Ishibashi Ningetsu; Ishibashi 1889a) bezieht. In „Bungaku to shizen“ bekräftigt Iwamoto seinen wiederholt vorgetragenen Standpunkt, dass die „grösste“ (saidai 最大) Literatur diejenige sei, die es schaffe, die Natur genau so darzustellen wie sie ist. Iwamoto verficht zudem die These, dass „Kunstwerke von äusserster Schönheit“ (gokubi no bijutsu 極美の美術) gar nicht in der Lage seien, Tugendloses (futoku 不徳) mit sich zu führen (MBgZ 32: 25). Auf diese Darlegungen Iwamotos antwortet Mori Ōgai in Nr. 50 der Kokumin no tomo 国民之友 (Juni 1889) mit seinem Artikel „,Bungaku to shizen“ wo yomu 文学卜自然」ヨ読ム“ („Bei der Lektüre von ,Literatur und Natur““; Mori 1889). Mori konzentriert sich in seinem Beitrag auf Iwamotos Trennung der Begriffe Grösse (dai 大) und Schönheit ( $b i$ 美). Unter Berufung auf die Aesthetischen Forschungen von Adolf Zeising (Frankfurt 1855) und Die Idee des Schönen und ihre Verwirklichung durch Natur, Geist und Kunst von Moritz Carrière (Leipzig 1859) lehnt Mori die von Iwamoto betriebene Trennung der Begriffe „Schönheit“ und „Grösse“ ab. In den genannten Quellen werde „Grösse“ als Variante, als Wirkung oder Prozess des „Schönen“ bezeichnet. Ausserhalb des „Schönen“ gebe es keine „Grösse“ und ausserhalb letzterer nicht erstere. Zwar habe der im Begriff „höchste Grösse“ enthaltene Begriff „Grösse“ eine grosse Wirkkraft im literarischen Werk, man könne sie aber nicht (analog zur Beziehung „Schönheit“ - „schöne Künste“) als die zentrale Eigenschaft des literarischen Kunstwerks kennzeichnen. Mori verwendet in seiner Darlegung die Wortzusammensetzung eruhāben (< deutsch „erhaben“) 高大 [kōdai] und bezieht sich damit ausdrücklich auf den im deutschen Idealismus seit Kant intensiv diskutierten Begriff (vollständige kommentierte Übersetzung von Moris Beitrag: Woldering 2015b). Kant definiert im Zweiten Buch seiner Kritik der Urteilskraft (1790) in $§ 25$ das Erhabene als „schlechthin gross“ und stellt es als magnitudo der messbaren, äusseren quantitas gegenüber (Kant 1968 [1790]: 169). Ishibashi verwendet wie Mori den Begriff kōdai 高大, gibt aber keinerlei Lesung dazu an. Es wäre also immerhin möglich, dass Ishibashi den von Mori über diese Schreibung eingeführten deutschen Begriff „Erhabenheit“ meint. Während aber Kant das Erhabene als ein subjektives und relatives Urteil kennzeichnet, behandelt Ishibashi es wie einen objektiven Befund. 
begrüssenswert, dass man sich Grossartigkeit, grossen Mut und hervorragende Grösse erhofft. Wenn man allerdings nicht aufzeigt, von welchem Charakter jene Menschen von wahrhafter Grossartigkeit, Grossmütigkeit und hervorragender Grösse sind, dann wird es wohl nicht wenige Irrtümer bezüglich derer Nachfolger geben. Ach, wie sollte wohl Grösse etwas sein, das sich auf die formale Anlage und Tatsachen ${ }^{75}$ gründet! Grösse liegt im Wesen, in empfindsamen Gedanken, im Herzen der Poesie. Anders gesagt: sie liegt hinter der formalen Anlage der Poesie. ${ }^{76}$ Ach, wie sollte es leicht sein, Grösse zu erreichen!

\section{Personen und persönliche Begebenheiten ${ }^{77}$}

Persönliche Begebenheiten gibt es erst dann, wenn es eine Person gibt. Eine Person gibt es nicht erst dann, wenn es persönliche Begebenheiten gibt. Deswegen sollte in der Poesie (besonders im Romane) stets die Person die Hauptsache sein, die persönlichen Begebenheiten sollten sich an sie anlehnen. Wenn man sich zunächst eine Person ersinnt, so zeigen sich deren persönliche Begebenheiten in Anlehnung an deren Empfinden, entstehen in Anlehnung an deren Gedanken. ${ }^{78}$ Die Person muss von Anfang bis Ende eine Einheit sein. Die persönlichen Begebenheiten sind beständigen Schwankungen und Wechseln unterworfen und ruhen nicht. Sollte man danach trachten, für die unruhigen persönlichen Begebenheiten eine feststehende Person zu verwenden, so entsteht letztendlich eine seltsame, unnatürliche Person, zusammengeflickt aus dem Ernsthaften, dem Schelm, dem Leidenschaftlichen und dem Gleichgültigen.

75 „Tatsachen“ für jijitsu 事実. Das darin enthaltene jitsu 実 („Wirklichkeit“) ist einer der beiden Kernbegriffe in Ishibashis Abhandlung.

76 „Formale Anlage der Poesie“ für shikei 詩形.

77 „Person“ für jinbutsu 人物, „persönliche Begebenheiten“ für jinji 人事. Unter dem selben Titel (Jinbutsu jinji) hat Ishibashi dieses Kapitel kurz zuvor (19. März 1890) selbständig in der Kōko shinbun veröffentlicht (Ishibashi 1890b). Am Ende des Kapitels kennzeichnet er es als systematisch nicht direkt zur Abhandlung gehörig.

78 „Gedanken“ für nen 念. Der hier abgeschlossene Gedanke variiert Tsubouchi Shōyōs These Shōsetsu no shunō wa ninjō nari, setai fūzoku kore ni tsugu 小説の首脳は人情なり、世態風俗こ れに次ぐ。 „Das Herzstück des Romanes ist das menschliche Gefühl; die Situation und das Verhalten folgen nach.“ (Shōsetsu shinzui 小説神髄, 1885/86; NKiBT 3: 68). Nanette Twine übersetzt diese These recht frei: „The main business of the novel is human nature. Social conditions and behaviour rank second." (Tsubouchi/Twine 1981: 23.) 
Wollte man diesem Defekt mit Gewalt ausweichen, so käme man am Ende nicht umhin, wegen der persönlichen Begebenheiten eine lästig grosse Zahl von Personen $\mathrm{zu}$ schaffen. Doch auch wenn man eine feststehende Person zur Hauptsache macht, mag man sie im Zusammenhang mit ihrer Situation, im Zusammenhang mit ihrer Position in einem gewissen Masse Wandlungen unterwerfen, auch wenn die persönlichen Begebenheiten unbeständig sein mögen. Auf diese Weise wird es möglich, stets Parallelität und Übereinstimmung zwischen dem Handeln und dem Charakter $^{79}$ der Person zu erreichen. Als ich neulich über das Oboroyo von Nansui ${ }^{80}$ und das Kuraku von Takamura ${ }^{81}$ eine Kritik verfasste und argumentierte, „Personen sollten um der Personen willen handeln. Man sollte unter keine Umständen Personen um einer Begebenheit willen auftreten lassen, “82 so war das aus genau diesem Grunde. Die motivische Anlage $^{83}$ sollte ganz von selbst aus dem Charakter der Personen hervorquellen. Wenn man eine Person steuert, um mit Gewalt eine motivische Anlage zu schaffen, so zeigt das nichts anderes als das Vergessen darum, dass im Roman das Hauptaugenmerk auf dem Menschen liegt. Es verrät auch das Unwissen darüber, dass das Kernmaterial des Romanes der Mensch ist. Mir scheint, dass

79 „Handeln“ für gyōi 行為, „Charakter“ für seishitsu 性質. Das Ideal einer Übereinstimmung zwischen Handeln und Charakter einer Person im Roman formulierte Ishibashi im Februar 1890, also einen Monat vor „Sō jitsu ron“ in „Maihime 舞姫“ (Die Tänzerin) in Kokumin no tomo 72 (Ishibashi 1890c) im Rahmen seiner Kritik an der gleichnamigen Erzählun des Mori Ōgai. Ishibashi kritisiert, dass der Protagonist Ōta Toyotarō in seinem grausamen Verhalten gegenüber seiner Geliebten gegen seinen eigenen Charakter handele. Mit dieser Kritik löste Ishibashi den sogenannten Maihime-Disput (Maihime ronsō 舞姫論争) aus. Mori konterte im April 1890 in „Kidori Hannojō ni atauru sho 気取半之丞に与ふる書“ (Kidori Hannojō zugeeignetes Schreiben); Shigarami zōshi; Mori 1890), dass schliesslich Shakespeare auch widersprüchliche Figuren wie den Hamlet geschaffen habe.

80 „Oboroyo“朧月夜 [sic!]: unvollständige Lesung (wohl ein Druckfehler der MBgZ-Ausgabe) des Romantitels Oborozukiyo 朧月夜 (Düstere Mondnacht; Shun'yōdō 春陽堂, 1890; Sudō 1890) von Sudō Nansui 須藤南翠 (1857-1920). Zusammen mit dem nachstehend erwähnten Aeba Kōson und anderen Autoren war Sudō an der Redaktion der seit Januar 1889 erscheinenden Zeitschrift Shin shōsetsu 新小説 (Neue Romane) beteiligt.

81 „Takamura“ 筀村: Lesungsvariante des Autorenvornamens von Aeba Kōson 饗庭筀村. Dessen hier erwähnte Erzählung Kuraku 苦楽 (Leid und Freude) erschien von März bis Juli 1889 in der Zeitschrift Shin shōsetsu (Aeba 1889).

82 Die hier erwähnte Kritik veröffentlichte Ishibashi 1889 unter dem Titel „,Kuraku‘ to ,Oborozukiyo“ no hikaku『苦楽』と『朧月夜』の比較“ (Vergleich von Kuraku und Oborozukiyo) im Juli 1889 in Nr. 55 der Kokumin no tomo 国民之友 (Ishibashi 1889c).

83 „Motivische Anlage“ für shukō 趣向. „Motiv“ meint hier im im engeren Sinne die Handlungsstränge und nicht die Gesamtkonzeption des Romanes. 
heutzutage viele Autoren in erster Linie eine motivische Anlage anstreben, dieser die szenische Gestaltung, ${ }^{84}$ das Auftragen der Farben, ${ }^{85}$ die Positionierung $^{86}$ und die Anordnung ${ }^{87}$ nachordnen, und dass erst danach endlich Gefühle und Gedanken der Personen entstehen. ${ }^{88}$ Deshalb sind die Personen dann nichts weiter als die Silhouette der motivischen Anlage. Und so vertritt ein einzelner Mensch dreie, viere, fünfe oder sechse zu Zeiten des Ruhmes, zu Zeiten des Scheiterns, zu Zeiten der Aufmunterung, zu Zeiten der Hoffnungslosigkeit, wenn man weinen soll, wenn man lachen soll. Man mag wohl sagen, dass dieses Vorgehen nicht übermässig mühselig ist, doch der Schaden dabei ist, dass es letztendlich die Feinheiten des Menschen nicht herauszuarbeiten vermag. Es vermag nicht, eine unvergängliche Wahrheit durch das ganze Werk strömen zu lassen. Der Geist ist dünn und schwach, und den Worten mangelt es an Gesundheit und Vollständigkeit. ${ }^{89}$ Wenn ein Roman seinen Wert verliert, dann muss man das hauptsächlich hierauf zurückführen. Wollen die vielen Schriften der Gegenwart innerhalb der tausend Ären auf die Suche nach menschlicher Weisheit gehen, so sollten sie sich nicht den Vorlieben des Zeitgeschmackes ergeben (denn das gemeine Auge erfreut sich allein an der motivischen Gestaltung), sondern sie sollten ihre Aufmerksamkeit auf das menschliche Leben richten. In der Tat liegt das Hauptaugenmerk des Romans auf dem Menschen, es liegt nicht auf de[ssen] Begebenheiten. ${ }^{90}$ Ich will nun ein Beispiel hierfür anführen. Das Keisei uta

84 „Szenische Gestaltung“ für fukei 布景.

85 „Auftragen der Farben“ für das nicht verifizierbare Kompositum tenshoku 点色.

86 „Positionierung“ für haichi 配置, womit die Positionierung von Romanfiguren gemeint ist.

87 „Anordnung“ für junjo 順序 im Sinne zeitlicher Abfolgen.

88 Ishibashi wiederholt hier dem Sinn nach die zentralen Aussagen, die Tsubouchi Shōyō in seinem Artikel „Meiji nijūni nen no chosakuka 明治廿二年の著作家 (Die Autoren des Jahres 1887, Yomiuri shinbun, 16. Jan. 1889; Tsubouchi 1889) vertrat. Mit dieser Übernahme der Tsubouchi-Thesen sucht Ishibashi womöglich, aus der Schusslinie der von Tsubouchi wiederholt vorgetragenen Kritik an der zeitgenössischen Literatur zu kommen. Tsubouchi hatte namentlich in „Meiji nijūni nen bungaku kai (omo ni shōsetsu kai) no fūchō 明治廿二年文学 界 (重に小説界) の風潮 (Strömungen der literarischen Welt (insbesondere der Romanwelt) des Jahres 1889; Yomiuri shinbun, 14. Jan. 1890; Tsubouchi 1890) Ishibashi als einen derjenigen genannt, deren Kritiken zu einer sorgfältigeren und raffinierteren Gestaltung literarischer Texte geführt haben, dass aber nun die Überbetonung von Sorgfalt und Rafinesse zulasten von Authentizität und Realitätsnähe in der Literatur gehe (KBHT 1: 86).

89 „Gesundheit und Vollständigkeit“ für kenzen 健全.

90 „Begebenheit“ für koto 事. Erneut klingt hier das von Tsubouchi Shōyō postulierte Primat der „menschlichen Gefühle“ (ninjō) vor den geschilderten Begebenheiten. 
shamisen von Kiseki ${ }^{91}$ ist mit Gewalt darauf angelegt, die Freudenviertel der drei grossen Städte in einem Werke erschöpfend zu behandeln, macht also - um der motivischen Gestaltung willen - Gebrauch von nutzlosen Personen. Demgegenüber scheinen mir Werke wie König Lear der Steppe des Turgenjev (Russland), ${ }^{92}$ von dem ich ein wenig lesen konnte, und das Fischermädchen des Bjørnson (Norvegen) ${ }^{93}$ die menschlichen Begebenheiten zur Nebensache zu machen und die Personen an die höchste Stelle zu setzen. ${ }^{94}$ Deswegen gibt es dort keine silhouettenhaften Personen.

Auf das Ende [dieses Abschnittes] schauend, sollte ich anfügen, dass die Person häufig aus der Idee, die persönlichen Begebenheiten häufig aus dem

91 „Keisei uta shamisen“傾城歌三味線, Titelvariante des Keisei uta shamisen けいせい歌三味 線(Lieder eines Freudenmädchens zur Laute, ein ukiyozōshi-Heft von Ejima Kiseki 江島其磧 (1666-1735) (Ejima/Kokumin tosho 1928 [1732]). Ejima führt den Leser darin anhand einer wechselvollen Rahmenhandlung der Protagonisten (einer weiterverkauften Prostituierten und des ihr folgenden Geliebten) durch die Welt der drei Bordellviertel Shimabara (Kyōto), Yoshiwara (Edo) und Shinmachi (Ōsaka). Ishibashi zitiert weiter unten einen Abschnitt aus diesem Text.

92 In seiner 1870 veröffentlichten Novelle Stepnoj korol' Lir (russ., Ein König Lear der Steppe) überträgt Ivan Sergejevich Turgenev (1818-1883) den Stoff des Shakespeare-Dramas King Lear (um 1605) in die Welt der Gutsbesitzer der russischen Provinz. Schon 1870 erschienen Übersetzungen von Turgenevs Novelle in mehreren europäischen Sprachen, von Adolf Gerstmann 1871 eine Übersetzung unter dem Titel Ein König Lear des Dorfes in Band 6 von Iwan Turgenjew's Ausgewählte Werke (Mitau: Behre; Turgenev/Gerstmann 1871 [1870]) und 1882 unter dem Titel Ein König Lear der Steppe (Übers. Adolf Gerstmann, Berlin: Janke; Turgenev/ Gerstmann 1871 [1882]). Ishibashis an das Deutsche anklingende Titelangabe Suteppe no Rearu ō legt die Vermutung nahe, dass er einer der beiden Gerstmann-Übersetzungen zur Hand hatte und deren Titel spontan übersetzte. Im Mittelpunkt der Novelle steht der Gutsbesitzer Charlov (die Entsprechung zu Shakespeares König Lear), dessen Persönlichkeitsentwicklung Turgenev mit der selben Eindringlichkeit schildert wie der Schöpfer der Vorlage dessen Figuren. Der von Ishibashi hier favorisierte Realitätsbezug wird bei Turgenev noch dadurch gesteigert, dass zahlreiche Gestalten aus Stepnoj korol' Lir deutlich erkennbar lebenden Personen aus der Turgenevs Umgebung nachgebildet sind.

93 Der norwegische Autor Bjørnstjerne Bjørnson (1832-1910) veröffentlichte 1869 den hier erwähnten Roman Fiskerjenten (schwed., Das Fischermädchen). Noch im selben Jahr erschien unter dem Titel Das Fischermädchen die erste deutsche, von August Peters besorgte Übersetzung (Bremen: Küthmann; Bjørnson/Peters 1869), 1877 unter dem gleichen Titel die von Wilhelm Lange besorgte Übersetzung (Leipzig: Reclam; Bjørnson/Lange 1877). Ishibashi gibt hier als Titel Gyoka no musume 魚家の娘 (Das Fischermädchen) an. Da ein solcher japanischer Übersetzungstitel nicht nachzuweisen ist, liegt die Vermutung nahe, dass Ishibashi die Lange-Übersetzung zur Hand hatte und hier spontan den Titel übertragen hat. Der stark vom französischen Realismus beeinflusste Bjørnson schildert mit psychologischem Tiefblick die Entwicklung eines phantasiebegabten Mädchens zur Künstlerin.

94 Die für Ishibashi relevante Gemeinsamkeit der beiden erwähnten literarischen Werke besteht darin, dass die persönliche Entwicklung der Protagonisten im Mittelpunkt steht. 
Wirklichen kommen. Davon, so scheint mir, machen die Grossen Europas regelmässig Gebrauch, und es ist das beste Mittel, um das Wesen der Poesie ${ }^{95}$ zu treffen. Zwar habe ich noch keine tiefschürfenden Forschungen ansammeln können und kann deshalb die Unabdingbarkeit nicht mit Sicherheit behaupten, doch so weit ich das bisher begreifen konnte, verhält es sich tatsächlich so. Ich möchte die mit Scharfblick ausgestatteten Meister der Sprache bitten, freundlicherweise keine Scheu vor einer Belehrung meiner Person zu haben, wann immer sie in dieser Sache etwas auf dem Herzen haben. In Bezug auf eine Abhandlung über die Idee und das Wirkliche hat das Verhältnis von Personen und menschlichen Begebenheiten keinen übermässigen Zusammenhang, doch glaube ich, dass es in wohl nicht geringem Masse dem Poeten zur Unterweisung dient. So hat es sich ergeben, dass ich es an dieser Stelle angefügt habe.

\section{Abkürzungen}

\begin{tabular}{|c|c|}
\hline Sigle & Auflösung \\
\hline DKJ & $\begin{array}{l}\text { Morohashi, Tetsuji 諸橋蹾次: Dai kanwa jiten 大漢和辞典. Tōkyō: } 12 \text { Bde. + Index. } \\
\text { Taishūkan shoten 大修館書店, } 1960\end{array}$ \\
\hline INZ & $\begin{array}{l}\text { Ishibashi Ningetsu zenshū 石橋忍月全集. Hrsg. Yamamoto, Kenkichi 山本健吉, } \\
\text { Inagaki, Tatsurō 稲垣達郎 und Odagiri, Susumu 小田切進. } 4 \text { Bde. Tōkyō: Yagi } \\
\text { shoten 八木書店. 1995-96 }\end{array}$ \\
\hline КВHT & $\begin{array}{l}\text { Kindai bungaku hyōron taikei 近代文学評論大系. Tōkyō: Kadokawa shoten 角川書 } \\
\text { 店.10 Bde. 1971-75 }\end{array}$ \\
\hline MBgZ & $\begin{array}{l}\text { Meiji bungaku zenshū 明治文学全集. } 99 \text { Bde. + Suppl. Tōkyō: Chikuma shobō 筑 } \\
\text { 摩書房, 1966-89 }\end{array}$ \\
\hline NKBT & $\begin{array}{l}\text { Nihon koten bungaku taikei 日本古典文学大系. } 100 \text { Bde. + Supp. und Indices. } \\
\text { Tōkyō: Iwanami shoten 岩波書店, 1958-68 }\end{array}$ \\
\hline NKiBT & $\begin{array}{l}\text { Nihon kindai bungaku taikei 日本近代文学大系. } 61 \text { Bde. Tōkyō: Kadokawa shoten } \\
\text { 角川書店, 1970-75 }\end{array}$ \\
\hline NMZ & $\begin{array}{l}\text { Nihon meicho zenshū 日本名著全集: Edo bungei no bu 江戸文芸之部. } 31 \text { Bde. } \\
\text { Tōkyō: Nihon meicho zenshū kankōkai 日本名著全集刊行会, 1926-29 }\end{array}$ \\
\hline NOAG & $\begin{array}{l}\text { Nachrichten der Gesellschaft für Natur- und Völkerkunde Ostasiens. Hamburg: } \\
\text { OAG, 1926- }\end{array}$ \\
\hline OGZ & $\begin{array}{l}\text { Ōgai zenshū 鴎外全集. } 33 \text { Bde. + } 2 \text { Suppl. Tōkyō: Iwanami shoten 岩波書店, } \\
\text { 1951-1956 }\end{array}$ \\
\hline
\end{tabular}

(continued)

95 „Wesen der Poesie“ für shigaku no seishin 詩学の精神. Das darin enthaltene Wort shigaku 詩 学 bezeichnet üblicherweise (die hier aus logischen Gründen nicht in Frage kommende) Poetik als Wissenschaft von der Poesie. 
(continued)

\begin{tabular}{ll}
\hline Sigle & Auflösung \\
\hline SKQS & $\begin{array}{l}\text { Siku quanshu 四庫全書. Hongkong: Chinese University of Hong Kong and Digital } \\
\text { Heritage Publishing Ltd. http://erf.sbb.spk-berlin.de/han/SikuQuanshu (Letzter }\end{array}$ \\
& Zugriff: 2017-03-24). \\
ZTB & Zoku Teikoku bunko 続帝国文庫. 50 Bände. Tōkyō: Hakubunkan 博文館, \\
& 1898-1903.
\end{tabular}

\section{Literaturverzeichnis}

\section{Primärliteratur}

Unter Primärliteratur werden die im Text behandelten Versionen des im Mittelpunkt stehenden „Sō jitsu ron"von Ishibashi Ningetsu sowie die mit ihnen in Form von Zitaten oder Anspielungen intertextuell verflochtenen Texte subsummiert.

Aeba, Kōson 饗庭筀村 (1889): „Kuraku“苦楽. In: Shin shōsetsu 新小説 (März-Juli).

Aeba, Kōson (1889-1890): Shōsetsu muratake 小説むら竹. 20 Bände. Tōkyō 東京: Shun’yōdō 春陽堂.

Bjørnson, Bjørnstjerne/Peters, August (1869): Das Fischermädchen. Norwegische Erzählung. [Fiskerjenten]. Bremen: Kühtmann.

Bjørnson, Bjørnstjerne/Lange, Wilhelm (1869): Das Fischermädchen. [Fiskerjenten]. Bremen: Kühtmann.

Bodenstedt, Friedrich (1887): Aus dem Nachlasse des Mirza-Schaffy. Neues Liederbuch von Friedrich Bodenstedt. Fünfzehnte vermehrte Auflage. Leipzig: Brockhaus.

Ejima, Kiseki 江島其磧 Kokumin Tosho (1928-1979 [1732]): Keisei uta shamisen けいせい歌三 味線. In: KNBT: 5: 417-519.

Gakutei, Kyūzan 岳亭丘山 Chisokukan, Shōkyoku 知足館松旭 (1828-1882): Shunketsu Shintō Suikoden 俊傑神稲水淓伝. In: ZTB 44-46.

Hahn, Werner (1879): Deutsche Poetik. Berlin: Hertz.

Inoue, Tsutomu 井上勤 (1883): Robinson hyōryū ki 魯敏孫漂流記. Tōkyō fu 東京府: Nagaoka Kagesuke 長尾景㢶.

Ishibashi, Ningetsu 石橋忍月 (1889a): „Jiji shinpō to Jogaku zasshi ni shissu“時事新報と女学 雑誌に質寸. In: Kokumin no tomo 国民之友 48 (Apr.). Moderner Nachdruck: INZ 3: 67-68.

Ishibashi, Ningetsu (1889b): „Kōson shi no ,Muratake““筀村氏の「むら竹」. In: Kokumin no tomo 国民之友 58 (Aug.). Moderner Nachdruck: INZ 3: 80-81.

Ishibashi, Ningetsu (1889c): „,Kuraku“ to ,Oborozukiyo“ no hikaku“『苦楽』と『朧月夜』の比 較. In: Kokumin no tomo 国民之友 55 (Juli). Moderner Nachdruck: INZ 3: 77-78.

Ishibashi, Ningetsu (1889d): Tsuyuko hime 露子姫. Tōkyō: Shun'yōdō 春陽堂. Moderner Nachdruck: MBgZ 23: 219-254.

Ishibashi, Ningetsu (1890a): „Dai“ 大. In: Kōko shinbun 江湖新聞, 05.04. Moderner Nachdruck: INZ 3: 153. 
Ishibashi, Ningetsu (1890b): ,Jinbutsu jinji“ 人物人事. In: Kōko shinbun 江湖新聞, 19.03. 1890. Moderner Nachdruck: INZ 3: 134-135.

Ishibashi, Ningetsu (1890c): „Maihime“舞姫. In: Kokumin no tomo 国民之友 72 (Feb.). Moderner Nachdruck: NKiBT 57: 88-91.

Ishibashi, Ningetsu (1890d): „Muratake Dai jūichi kan“むら竹第十一巻. In: Kokumin no tomo 国民之友 (70). Moderner Nachdruck: INZ 3: 110-112.

Ishibashi, Ningetsu (1890e): „Shiika no seishin oyobi yojō“詩歌の精神及余情. In: Kokumin no tomo 国民之友 69 (Jan.). Moderner Nachdruck: INZ 3: 103-106.

Ishibashi, Ningetsu (1890f): „Yomiuri shinbun Hito samazama“読売新聞人さまざま. In: Yomiuri shinbun 読売新聞, 22.06. Moderner Nachdruck: INZ 3: 75-76.

Iwamoto, Yoshiharu 䉷本善治 (1889): „Kokumin no tomo dai yonjūhachi gō Bungaku to shizen“ 国民之友第四十八号文学々自然. In: Jogaku zasshi 女学雑誌 159 (Apr.). Moderner Nachdruck: KBHT 1: 67-68.

Kant, Immanuel (1968 [1790]): Kritik der Urteilskraft. In: Immanuel Kant: Werke, Bd. 10 (Hg. Wilhelm Weischedel; Frankfurt am Main: Suhrkamp): 73-442.

La Bruyère, Jean de (1886 [1688]): Les caractères. Tours: Cattier.

Minagawa, Kien皆川淇園 (1771): Kien shiwa 淇園詩話. Moderner Nachdruck: Nihon shiwa sōsho 日本詩話叢書 5 (Hgg. Ikeda, Roshū 池田蘆洲; Kokubu, Takatane 国分高胤; Tōkyō 東京: Ōtori shuppan 鳳出版): 177-226.

Mori, Ōgai 森鴎外 (1889): ,,Bungaku to shizen“ wo yomu“「文学卜自然」ヨ読ム. In: Kokumin no tomo 国民之友 50 (Mai). Moderner Nachdruck: KBHT 1: 69-75.

Mori, Ōgai (1890): „Kidori han no jō ni atauru sho“気取半之丞に与ふる書. In: Shigarami zōshi しがらみ草紙 (April). Moderner Nachdruck: NKiBT 57: 92-99.

Morita, Shiken 森田思軒 (1889): „Konnichi no bungakusha“今日の文学者. In: Kokumin no tomo 国民之友 48 (Apr.) Moderner Nachdruck: KBHT 1: 59-61.

Nishimori, Takeki 西森武城 (1888): Hyakunin hyakuiro 百人百色 (Ukiyo no shashin 浮世写真). Tōkyō 東京: Kyōryū sha 共隆社.

Nishimori, Takeki (1889): „Hito samazama“人さまざま. In: Yomiuri shinbun 読売新聞, 11. Juni - 31. August.

Oberbreyer, Max (1874): Theophrast's Charakterbilder. Leipzig: Reclam (Reclams Universalbibliothek, 619).

Platen-Hallermünde, August von (1847): Epigramme. In: August von Platen-Hallermünde: Gesammelte Werke des Grafen August von Platen, Bd. 2 (Vw. Gödeke, Karl. Stuttgart, Tübingen: Cotta).

Sei, Shōnagon 清少納言 (1000): Makura no sōshi 枕草子. Moderner Nachdruck: NKBT 19: 5-402.

Seihakudō Kōfū, 生白堂行風 /Asakura, Kaichō 朝倉懐中 (1672): Gosen ikyoku shū 後撰夷曲集. Moderner Nachdruck: NMZ 19: 185-280.

Shiba, Shirō 柴四朗 (1885-1897): Kajin no kigū 佳人之奇遇. Tōkyō 東京: Hakubundō 博文堂.

Sudō, Nansui 須藤南翠 (1890): Oborozukiyo 朧月夜. Tōkyō 東京: Shun’yōdō 春陽堂.

Suehiro, Tetchō 末広鉄腸 (1887): Setchūbai 雪中梅. Tōkyō 東京: Hakubundō 博文堂.

Tokutomi, Sohō 徳富蘇峰 (1889): „Genron no fujiyū to bungaku no hattatsu“言論の不自由と文 学の発達. In: Kokumin no tomo 国民之友 48 (April). Moderner Nachdruck: KBHT 1: 62-66.

Tsubouchi, Shōyō 坪内逍遥 (1889): „Meiji nijū ni nen no chosaku ka“明治廿二年の著作家. In: Yomiuri shinbun 読売新聞, 15.01. 
Tsubouchi, Shōyō 坪内逍遥 (1890): „Meiji nijūni nen bungaku kai (omo ni shōsetsu kai) no fūchō“明治廿二年文学界（重に小説界）の風潮. In: Yomiuri shinbun 読売新聞, 14.01. Moderner Nachdruck: KBHT 1: 86-88.

Turgenev, Ivan/Gerstmann, Adolf (1870): Ein König Lear des Dorfes. [Stepnoj korol' Lir]. In: Ivan Turgenev: Iwan Turgenjew’s Ausgewählte Werke, Bd. 6 (Hg. N.N., Mitau: Behre).

Ushiyama, Kakudō 牛山鶴堂 (1887): Robinson hyōryū ki 魯敏孫漂流記 (Shin'yaku 新訳). Tōkyō fu 東京府: Shun'yōdō 春陽堂.

Yano, Ryūkei 矢野龍渓 (1890): Ukishiro monogatari 浮城物語 (Hōchi ibun 報知異聞). Tōkyō 東京: Hōchi sha 報知社. Moderner Nachdruck: MBgZ 15: 77-178.

\section{Sekundärliteratur}

Neben der Forschungsliteratur werden hier auch Übersetzungen der Primärliteratur (Abschn. 17) nachgewiesen.

Gethmann-Siefert, Annemarie (2005): Einführung in Hegels Ästhetik. München, Paderborn: Finck (Uni Taschenbücher, 2646).

Keene, Donald (1961): Major Plays of Chikamatsu. New York: Columbia University Press.

Kuroki, Shōko 黒木祥子 (1985): „Kinsei zenki kyōka no naka no kayō“近世前期狂歌の中の歌謡. ,Kokon ikyoku shū‘ ,Gosen ikyoku shū‘ ,Gin’yō Ebisu uta shū‘ no shuhō ni tsuite“『古今夷曲 集』『後撰夷曲集』『銀葉夷歌集』. In: Jinbungaku ronshû 人文学論集 3: 51-64.

Schamoni, Wolfgang (1975): „Die Entwicklung der Romantheorie in der japanischen Aufklärungsperiode“. In: NOAG 118: 9-39.

Sei, Shōnagon 清少納言 Watanabe, Mamoru (1952 [1000]): Das Kopfkissenbuch der Hofdame Sei Shonagon. Zürich: Manesse.

Tsubouchi, Shōyō 坪内逍遥 Twine, Nanette (1885-1886 [1981]): The Essence of the Novel. Tsubouchi Shōyō. Queensland: University of Queensland Press (Occasional Papers, 11).

Woldering, Guido (2015a): „Bijutsu no hongi (1885) und Shōsetsu sōron (1886) von Futabatei Shimei. Die Emanzipation der japanischen Erzählprosa zu einer Kunstform“. In: Bunron 文論 2: 15-47. Online verfügbar unter http://crossasia-journals.ub.uni-heidelberg.de/ index.php/bunron/article/view/658 (letzter Zugriff: 12. Feb. 2017).

Woldering, Guido (2015b): „Fiktion und Wirklichkeit in der japanischen Literaturtheorie der Jahre 1850 bis 1890: Mori Ōgais ,Bungaku to shizen wo yomu“ (1889)“. In: NOAG 189-190: 57-126.

Notes: Zu den verschiedenen Textfassungen und der Grundlage der hier gegebenen Übersetzung siehe Teil I in Asiatische Studien /Études Asiatiques 71.1. 